CAHIER DE RECHERCHE \#1612E

WORKING PAPER \#1612E

Département de science économique

Department of Economics

Faculté des sciences sociales

Faculty of Social Sciences

Université d'Ottawa

University of Ottawa

\title{
Flexible Functional Forms and Curvature Conditions: Parametric Productivity Estimation in Canadian and U.S. Manufacturing Industries*
}

\author{
J akir Hussain $^{\dagger}$ and J ean-Thomas Bernard ${ }^{\ddagger}$
}

August 2016

\footnotetext{
*We thank Yazid Dissou for sharing the Canadian KLEMS data set, obtained from Statistics Canada. We would like to thank Samuel Gamtessa, Lynda Khalaf, Pierre Brochu, Jianming Tang for valuable comments and suggestions. We would also like to thank the participants at North American Productivity Workshop IX, June 2016, Quebec City, and 49th Annual Conference of Canadian Economics Association, May 2015, Toronto, for helpful comments and discussions.

${ }^{\dagger}$ Department of Economics, University of Ottawa, 120 University Private, Ottawa, Ontario, Canada. K1N 6N5; email: jhussain@uOttawa.ca.

₹ Department of Economics, University of Ottawa, 120 University Private, Ottawa, Ontario, Canada, K1N 6N5; email: jbernar3@uOttawa.ca.
} 


\begin{abstract}
It is well-known that econometric productivity estimation using flexible functional forms often encounter violations of curvature conditions. However, the productivity literature does not provide any guidance on the selection of appropriate functional forms once they satisfy the theoretical regularity conditions. In this paper, we provide an empirical evidence that imposing local curvature conditions on the flexible functional forms affect total factor productivity (TFP) estimates in addition to the elasticity estimates. Moreover, we use this as a criterion for evaluating the performances of three widely used locally flexible cost functional forms - the translog (TL), the Generalized Leontief (GL), and the Normalized Quadratic (NQ) - in providing TFP estimates. Results suggest that the NQ model performs better than the other two functional forms in providing TFP estimates.
\end{abstract}

Key words: Technical change, Productivity, Flexible functional forms, Translog (TL), Generalized Leontief (GL), Normalized Quadratic (NQ), Cost function, Concavity.

JEL Classification: C22, F33.

\title{
Résumé
}

Il a été observé à maintes reprises que les conditions du second ordre en accord avec la théorie économique ne sont pas satisfaites lorsque la productivité totale des facteurs(PTF) est mesurée en faisant usage de formes fonctionnelles flexibles. Cependant les études antérieures ne fournissent pas de guide dans le choix de la forme fonctionnelle lorsque les conditions du second ordre sont satisfaites. Dans ce texte, nous présentons des résultats obtenus à partir de données réelles montrant que l'imposition des conditions du second ordre aux formes fonctionnelles flexibles influence la mesure de la PTF. D'ailleurs c'est le critère que nous utilisons pour évaluer la performance de trois formes fonctionnelles flexibles qui sont fréquemment utilisées pour obtenir des évaluations de PTF, à savoir, la fonction translog (TL), la fonction Léontief généralisée( $L G)$ et la fonction quadratique normalisée(QN). Nos résultats suggèrent que cette dernière offre la meilleure performance de trois formes fonctionnelles flexibles à ce sujet.

Mots clés : Changement technologique, productivité totale de facteurs, forme fonctionnelle, translog (TL), Léontief généralisée (LG), quadratique normalisée (QN), fonction de cout, concavité.

Classification JEL : C22, F33. 


\section{Introduction}

The standard econometric approach to modelling the rate and biases of technical change, introduced by Binswanger (1974a,b), involves representing the rate and biases through constant time trends in a flexible functional form and estimating the unknown parameters using econometric methods. ${ }^{1}$ See Jin and Jorgenson (2010) for a list of studies that rely on this widely used approach for modelling technical change. It is well known that among the regularity conditions - positivity, monotonicity, and curvature - that are implied by economic theory, curvature conditions are often violated in empirical applications of flexible functional forms (see Diewert and Wales, 1987; Ryan and Wales, 2000).

Theoretical curvature properties are crucial, especially, in estimating the flexible functional forms. For example, Diewert and Wales (1987) noted that, it is necessary for the estimated production and utility functions used in applied general equilibrium models to globally satisfy the theoretical curvature conditions. Empirical rejection of concavity by the estimated cost function casts a doubt on the underlying true model of production as it could lead to a non-continuous input demand function. Moreover, any inferences based on this result would be unconvincing, since the input demand functions derived from the cost function may not be cost minimizing due to the violation of curvature property. This casts a serious doubt on the assumption that firms in the sample are cost minimizers.

No parametric restrictions can ensure global curvature conditions while maintaining flexibility in the translog (TL) and the Generalized Leontief (GL) functional forms as this property is data dependent. Violation of curvature conditions by the translog and the GL has led Diewert and Wales (1987) to develop more complex locally flexible functional form — the Normalized Quadratic (NQ) (see Diewert and Wales, 1987) -

\footnotetext{
${ }^{1}$ Slade (1989) criticizes the traditional method of modelling the state of technology by including time trend in the production or cost function and, instead, suggests the use of state-space approach through the Kalman filter in estimating technical change. More recently, Jin and Jorgenson (2010) replaces the constant time trend by latent variables and use the Kalman filter to estimate the latent variables in the translog model.
} 
which allows imposing global curvature conditions and maintaining flexibility at the same time. However, instead of imposing global concavity on the translog and the GL cost functions, Ryan and Wales (2000) propose a method to impose it locally, at a chosen reference point. They show that their procedure of curvature imposition does not destroy the flexibility property of the functional forms and it leads to satisfaction of curvature property at all data points for their data set. Since they do not find any impact on productivity estimates they conclude that the effect of imposing concavity is limited, in their case, only to the price responses. However, the productivity literature does not provide any guidance on the selection of appropriate flexible functional forms once they satisfy all theoretical regularity conditions (see Feng and Serletis, 2008).

In this paper we provide empirical evidence that imposing local concavity on the translog and the GL cost functions affects the productivity estimates, in addition to its effect on the elasticity estimates which has attracted the attention in the literature thus far. In doing so, we employ three well-known locally flexible functional forms the translog, the GL, and the NQ cost functions, and present an empirical comparison and evaluation of the effectiveness of these cost functions in providing total factor productivity (TFP) estimates when they satisfy all theoretical regularity conditions. ${ }^{2}$ We use the difference in TFP estimates, with and without curvature constraint, as a criterion for comparing performances of different functional forms. In estimating the models we utilize manufacturing KLEM (capital, labour, energy, and material) data covering the period from 1961 to 2003 for Canada and the US. Moreover, we follow Ryan and Wales (2000) to impose local curvature conditions on the translog and the GL models, and for the NQ we impose global curvature conditions following Diewert and Wales (1987).

While comparing the functional forms in providing TFP estimates, we provide examples of all three possible scenarios: First, the cases where all three regularity conditions are satisfied without curvature being imposed; second, the cases where

\footnotetext{
${ }^{2}$ Fisher et al. (2001) provide an empirical evaluation of the performances of eight flexible functional forms in the context of consumer demand.
} 
curvature conditions are not satisfied even with local curvature being imposed; finally, the cases where imposing curvature resulted in the satisfaction of regularity conditions. We also provide substitution and price elasticity estimates of factors of production in the U.S. and Canadian manufacturing industries.

Feng and Serletis (2008) estimate TFP in the U.S. manufacturing industry using four flexible functional forms. In addition to the three functional forms that we use in this study, they also estimate the asymptotically ideal model (AIM) cost function. Although they impose concavity on the three locally flexible functional forms using the same techniques that we use in this study, only the NQ model satisfies curvature conditions. As a result, they provide a comparison between the NQ and the AIM cost functions - the only models that satisfy all regularity conditions. Using a smoothed Fisher TFP index as benchmark they conclude that the AIM, with curvature imposed, performs better in estimating TFP. However, there is not a single case where concavity is satisfied without curvature being imposed and as a result they are unable to analyze this aspect. Moreover, since they fail to include the translog and the GL in the analysis they could not analyze the impact of local curvature imposition. Based on a different criterion we provide comparisons between all three locally flexible functional forms that we consider in this study. We also compare the effects of local and global curvature imposition while Feng and Serletis (2008) evaluate the effect of global curvature imposition. My estimation results provide us the opportunity to analyze all three possible scenarios mentioned earlier which is not the case in Feng and Serletis (2008).

My empirical findings support the result provided by Feng and Serletis (2008) that imposing local curvature conditions on the translog and the GL does not always assure theoretical regularity conditions at all data points in the sample. Moreover, using the estimation results we show that when curvature condition is met by imposition, the NQ model performs better in providing TFP estimates than the translog and GL models, at least for our data sets. However, the GL model performs equally well when all regularity conditions are satisfied without curvature being imposed. My findings also 
provide evidence that local curvature imposition on the translog and the GL models affect the productivity estimates. Based on our results we argue that since concavity is not guaranteed in the translog and the GL models even with curvature being imposed, functional forms with global curvature conditions appear to be a better choice for econometric productivity estimation.

The rest of the paper is organized as follows. Section 2 reviews the theoretical background on different approaches to productivity measurement. Section 3 presents the functional forms and relevant techniques for imposing curvature conditions while Section 4 discusses the index number techniques used in this study. Section 5 describes the data sets and outlines the empirical estimation strategies. Section 6 reports the estimation results, and finally, Section 7 concludes.

\section{Theoretical Background}

\subsection{Productivity Measurement}

Recent shift in attention to the rate and biases of technical change has put the econometric approach to productivity measurement in the forefront of empirical productivity analysis even though the most commonly utilized approach is the index number technique. ${ }^{3}$ See, for example, Acemoglu (2002a,b, 2007), Jaffe et al. (2003), Jin and Jorgenson (2010) for different applications of the biases of technical change. As opposed to the index number approach, it is ideal to have a productivity measure that would also shed some light on the production structure, for example, the factor biases and the elasticities of factor substitution. Accurate information on these estimates is vital for policy making, in particular energy policies. See, for example, León-Ledesma et al. (2010) for a discussion on the importance of parameters of the elasticity of substitution

\footnotetext{
${ }^{3}$ See Hulten (2001) for a discussion on the historical development of quantitative analysis of productivity. For a brief discussion on various approaches to productivity measurement see Feng and Serletis (2008). Using simulation Van Biesebroeck (2007) provides a discussion on the robustness of productivity estimates obtained by different measurement approaches. Also for a comparison of growth accounting approaches in measuring TFP, see Norsworthy (1984).
} 
and the direction of technical change to different policy implications. In what follows, we briefly discuss the index number and the econometric approaches to productivity measurement. ${ }^{4}$

With the index number approach rates of change of total factor productivity is calculated by dividing an index of output(s) by an index of inputs. To measure the rate of technical change a share weighted index of rates of change in inputs is deducted from the rate of change of output,

$$
\frac{\partial y / \partial t}{y}-\sum_{i=1}^{n} s_{i} \frac{\partial x_{i} / \partial t}{x_{i}}
$$

where inputs $\mathbf{x} \geq 0$ are used to produce output $y$, and $s_{i} \equiv \frac{p_{i} x_{i}}{C}$.

The econometric approach typically involves estimation of a production or cost function and then it is differentiated with respect to time. Technical change is associated with any temporal shift in the production or cost frontier, and under constant returns to scale both production and cost function approaches would yield equivalent results. With the cost function approach the existence of a cost function,

$$
C=C(\mathbf{p}, y, t)
$$

that relates the vector of factor prices $\mathbf{p}$, output $y$, and a summary of the state of technology $t$ with total cost $C$, is assumed. ${ }^{5}$ It is a solution to the following cost minimization problem

$$
\min _{\mathbf{x}} \mathbf{p x} \quad \text { s.t. } \quad y \geq f(\mathbf{x}, t), \mathbf{x} \geq \mathbf{0} .
$$

and the corresponding dual of the following strictly monotonic, strictly quasi-concave,

\footnotetext{
${ }^{4}$ As in Feng and Serletis (2008), this section builds heavily on standard notations in the literature, mainly from Berndt (1991).

${ }^{5}$ For notational simplicity we suppress the time subscripts.
} 
and continuously twice differentiable production function,

$$
y=f(\mathbf{x}, t)
$$

which transforms a vector of inputs $\mathbf{x} \geq \mathbf{0}$ into output $y$. To be able to successfully represent the underlying production process in (3), the cost function (2) must be nonnegative, non-decreasing in $y$ and $\mathbf{p}$, and linear homogeneous and concave in $\mathbf{p}$. Under constant returns to scale equation (2) becomes

$$
C(\mathbf{p}, y, t)=y c(\mathbf{p}, t)
$$

where $c$ is the corresponding unit cost function. Invoking Shephard's Lemma yields the optimal factor demand equations,

$$
x_{i}=\partial C(\mathbf{p}, y, t) / \partial p_{i}, \quad i=1, \ldots, n
$$

Rate of technical change in the cost function approach is measured in the following way,

$$
T F P=-\frac{\partial \ln C(\mathbf{p}, y, t) / \partial t}{\partial \ln C(\mathbf{p}, y, t) / \partial \ln y}
$$

where $\partial \ln C(\mathbf{p}, y, t) / \partial t$ represents the rate of cost diminution and $\partial \ln C(\mathbf{p}, y, t) / \partial \ln y$ represents the inverse of rate of returns to scale which equals to unity under constant returns to scale,

$$
T F P=-\frac{\partial \ln C(\mathbf{p}, y, t)}{\partial t}=-\frac{\partial C(\mathbf{p}, y, t) / \partial t}{C} .
$$

Hence, an upward shift in the production function is equal to an equivalent downward shift in the cost function under constant returns to scale. After assuming different functional forms for $C$ in (2), we can easily obtain the estimates of TFP by estimating the parameters of $C$.

The effects of technological change on factor use, which is often referred to as the 
input bias due to technical change, can also be measured as follows

$$
\tau_{i}=\frac{\partial \ln x_{i}(\mathbf{p}, y, t)}{\partial t}
$$

They provide us with the information about how the usage of inputs changes as a result of technical change and reflect that part of changes in input use which is not due to output change or to factor substitution as a result of relative change in factor prices. With regards to the direction of bias, if $\tau_{i}>0(<0)$, then technical change is factor $i$ using (saving).

Furthermore, for the dual cost function in (2) factor substitution can also be calculated using the Morishima elasticities of substitution (see Blackorby and Russell, 1989),

$$
\sigma_{i j}^{m}(\mathbf{p}, y, t)=\frac{p_{j} C_{i j}(\mathbf{p}, y, t)}{C_{i}(\mathbf{p}, y, t)}-\frac{p_{j} C_{j j}(\mathbf{p}, y, t)}{C_{j}(\mathbf{p}, y, t)}
$$

where the $i$ and $j$ subscripts refer to the first and second partial derivatives of equation (4) with respect to the corresponding input prices. A positive (negative) $\sigma_{i j}^{m}$ indicates that input $j$ is a Morishima substitute (complement) for input $i$. Moreover, the input price elasticities are computed as

$$
\eta_{i j}=\frac{\partial \ln x_{i}(\mathbf{p}, y, t)}{\partial \ln p_{j}}=\frac{\partial x_{i}(\mathbf{p}, y, t)}{\partial p_{j}} \frac{p_{j}}{x_{i}(\mathbf{p}, y, t)}
$$

The relationship between the price and substitution elasticities can be postulated as,

$$
\sigma_{i j}^{m}=\eta_{i j}-\eta_{j j}
$$

\subsection{Curvature Conditions}

A crucial requirement about the cost function is that it must be concave in prices.

Necessary and sufficient condition for concavity is that the Hessian matrix of the cost function be negative semi-definite. To check for concavity, eigenvalues of the estimated 
Hessian matrix of the cost functions are computed at each point in the sample space. Morey (1986) provides an excellent overview of the curvature conditions and checking process for empirical applications of different flexible functional forms.

As mentioned earlier, curvature properties are often violated in empirical applications of flexible functional forms. A number of studies report that the estimated functional forms fail to satisfy this property. See, for example, Wills (1979), Slade (1989), Diewert and Wales (1987), Delorme and Lester (1990), Barnett and Serletis (2008). One way to deal with these violations is to perform some simple checking procedures. For example, Caves et al. (1980) check whether the parameter generating positive own price elasticity is significantly different from a value of the parameter generating non-positive elasticity estimate. Another simple procedure is adopted by Slade (1989) which involves checking whether the concavity violations occurred by chance. This procedure uses a technique developed by Geweke (1986) and involves Monte Carlo simulation method to generate replications of the estimated coefficients from a multivariate normal distribution.

The other available option is to impose local or global curvature restrictions. Curvature restrictions are imposed in many different contexts. For applications, in consumer theory, see, for example, Ryan and Wales (1998), Moschini (1999), in case of production theory, see Gallant and Golub (1984), Terrell (1996), and Ryan and Wales (2000), and in the context of GNP functions, see Kohli (1992) for example. Global curvature restrictions can be imposed using Cholesky decomposition on the NQ cost function without destroying its flexibility property. For a discussion on the restrictions and implementation technique, see Diewert and Wales (1987) and Wiley et al. (1973). However, imposing global restrictions on the translog and the GL cost functions destroys their flexibility property.

Instead of imposing global concavity, Ryan and Wales (2000) propose a method to impose it locally at a chosen reference point. Using the same dataset used by Diewert and Wales (1987), they show that their procedure of imposing local curvature 
guarantees concavity at the data point where it is imposed without destroying the flexibility of the functional form. Although imposing concavity on a single observation does not guarantee concavity for other data points, they hope that a judicious choice of point of imposition may lead to satisfaction of concavity at most or all data points. This procedure of local curvature imposition provides the expected concavity coverage for their data set; however, this result is not universal. Other techniques for imposing local curvature conditions include the general computational methods used by Lau (1978) and Gallant and Golub (1984), and the Bayesian approach used by Chalfant and Wallace (1992), Terrell (1996), and Griffiths et al. (2000).

In what follows, we take the econometric approach to productivity measurement for three Canadian and two US energy intensive industries and provide a comparison between three widely used locally flexible cost functional forms - the translog, the GL, and the NQ cost functions. For all cost functional forms, we assume cross-equation symmetry restrictions, linear homogeneity in prices as well as constant returns to scale in the production process as a maintained hypothesis. Obviously one can test for whether these assumptions actually hold.

\section{Locally Flexible Functional Forms}

\subsection{The Translog Cost Function}

If we assume that the unit cost function in (4) takes the translog functional form (Christensen et al., 1971, 1973), then we get

$$
\begin{aligned}
\ln C(\mathbf{p}, y, t)= & \beta_{0}+\ln y+\sum_{i=1}^{n} \beta_{i} \ln p_{i}+\frac{1}{2} \sum_{i=1}^{n} \beta_{i i}\left[\ln p_{i}\right]^{2}+ \\
& \frac{1}{2} \sum_{i \neq j}^{n} \sum_{j=1}^{n} \beta_{i j} \ln p_{i} \ln p_{j}+\sum_{i=1}^{n} \beta_{i t} t \ln p_{i}+\beta_{t} t+\frac{1}{2} \beta_{t t} t^{2}
\end{aligned}
$$


Together with the assumption of symmetry — that is, $\beta_{i j}=\beta_{j i}$ - homogeneity of degree one in prices imposes the following constraints

$$
\sum_{i=1}^{n} \beta_{i}=1, \quad \sum_{i=1}^{n} \beta_{i j}=\sum_{j=1}^{n} \beta_{i j}=\sum_{i=1}^{n} \beta_{i t}=0 .
$$

The corresponding factor cost share equations are

$$
s_{i}=\frac{p_{i} x_{i}}{C}=\beta_{i}+\beta_{i i} \ln p_{i}+\sum_{j \neq i}^{n} \beta_{i j} \ln p_{j}+\beta_{i t} t
$$

Equation (14) imposes another adding-up restriction, $\sum_{i=1}^{n} s_{i}=1$, which already holds through the assumption of linear homogeneity in prices. It is to be noted that as all parameters of the share equations are also present in the cost function we can directly estimate (12). However, joint estimation of (12) and (14) as a system of equations reduces possible high degree of multicollinearity in the independent variables and increases efficiency and degrees of freedom available.

However, as mentioned earlier, in empirical applications failure of the translog to satisfy the regularity conditions is very common. To overcome this problem local concavity can be imposed at a chosen reference point following the route suggested by Ryan and Wales (2000). Diewert and Wales (1987) show that the Hessian of the translog cost function will be negative semidefinite, providing $C(\mathbf{p}, y, t)>0$, if and only if the following matrix is negative semidefinite

$$
\mathbf{H}=\mathbf{B}-\mathbf{S}^{n}+\mathbf{S} \mathbf{S}^{\prime}
$$

where $\mathbf{B}=\left[\beta_{i j}\right]$ is the $n \times n$ symmetric matrix of $\beta_{i j}, \mathbf{S}=\left[s_{1}, \ldots, s_{n}\right]^{\prime}$ is the vector of input shares, and $\mathbf{S}^{n}$ is the $n \times n$ diagonal matrix of input shares. 
To impose local concavity, equation (12) is rewritten as

$$
\begin{aligned}
\ln C(\mathbf{p}, y, t)= & \beta_{0}+\ln y+\sum_{i=1}^{n} \beta_{i} \ln p_{i}+\frac{1}{2} \sum_{i=1}^{n} \beta_{i i}\left[\ln p_{i}\right]^{2}+\frac{1}{2} \sum_{i \neq j}^{n} \sum_{j=1}^{n} \beta_{i j} \ln p_{i} \ln p_{j}+ \\
& \sum_{i=1}^{n} \beta_{i t} t \ln p_{i}+\beta_{t}\left[t-t^{*}\right]+\frac{1}{2} \beta_{t t}\left[t-t^{*}\right]^{2}
\end{aligned}
$$

where $t^{*}$ is the chosen reference point - that is, the point of imposition of local concavity — where all prices are normalized to one. The corresponding input share equations are

$$
s_{i}=\beta_{i}+\beta_{i i} \ln p_{i}+\sum_{j \neq i}^{n} \beta_{i j} \ln p_{j}+\beta_{i t}\left[t-t^{*}\right] .
$$

Normalizing all input prices to one at $t^{*}$ makes $s_{i}=\beta_{i}$ for all $i$ at this data point. The $i j^{\text {th }}$ element of $\mathbf{H}$ evaluated at $t^{*}$ is

$$
\mathbf{H}_{i j}=\beta_{i j}+\beta_{i} \beta_{j}-\beta_{i} \delta_{i j} \quad i, j=1, \ldots, n,
$$

where $\delta_{i j}=1$ if $i=j$ and 0 otherwise. Curvature is imposed at the reference point, $t^{*}$, by setting $\mathbf{H}=-\mathbf{A} \mathbf{A}^{\prime}$, where $\mathbf{A}$ is a lower triangular matrix with elements $a_{i j}$ for $i \geq j$ and 0 elsewhere. Now solving for $\mathbf{A}$ in (18) gives us

$$
\beta_{i j}=-\left(\mathbf{A A}^{\prime}\right)_{i j}+\beta_{i} \delta_{i j}-\beta_{i} \beta_{j} \quad i, j=1, \ldots, n .
$$

where $\left(\mathbf{A} \mathbf{A}^{\prime}\right)_{i j}$ is the $i j^{t h}$ element of $\mathbf{A} \mathbf{A}^{\prime}$. 
Equation (19) gives us the following relationships, in the case of four factors:

$$
\begin{array}{ll}
\beta_{11}=-a_{11}^{2}+\beta_{1}-\beta_{1}^{2}, & \beta_{12}=-a_{11} a_{21}-\beta_{1} \beta_{2}, \\
\beta_{13}=-a_{11} a_{31}-\beta_{1} \beta_{3}, & \beta_{14}=-a_{11} a_{41}-\beta 1 \beta_{4}, \\
\beta_{22}=-\left(a_{21}^{2}+a_{22}^{2}\right)+\beta_{2}-\beta_{2}^{2}, & \beta_{23}=-\left(a_{21} a_{31}+a_{22} a_{32}\right)-\beta_{2} \beta_{3}, \\
\beta_{24}=-\left(a_{21} a_{41}+a_{22} a_{42}\right)-\beta_{2} \beta 4, & \beta_{33}=-\left(a_{31}^{2}+a_{32}^{2}+a_{33}^{2}\right)+\beta_{3}-\beta_{3}^{2}, \\
\beta_{34}=-\left(a_{31} a_{41}+a_{32} a_{42}+a_{33} a_{43}\right)-\beta_{3} \beta_{4}, & \beta_{44}=-\left(a_{41}^{2}+a_{42}^{2}+a_{43}^{2}+a_{44}^{2}\right)+\beta_{4}-\beta_{4}^{2} .
\end{array}
$$

Replacing the elements of $\mathbf{B}=\left[\beta_{i j}\right]$ in (16) and (17) by the above relationships and estimating $a_{i j}$ will ensure that the translog cost function will be concave at the normalization point $t^{*}$ and may also encompass concavity at other data points in the sample. However, this replacement makes the system of equations nonlinear in parameters $a_{i j}$. Equation (7) yields the rate of technical change for the translog as

$$
T F P=-\frac{\partial \ln C(\mathbf{p}, y, t)}{\partial t}=-\left(\beta_{t}+\beta_{t t} t+\sum_{i=1}^{n} \beta_{i t} \ln p_{i}\right)
$$

Moreover, following Jin and Jorgenson (2010), we decompose the rate of technical change into autonomus and induced technical change components. Together, the first two parts on the right hand side, which depends only on changes in the level of technology, gives us the rate of autonomous technical change. The last part on the right hand side of (20), which depends on the prices as well as the biases of technical change, measures the contribution to rate of productivity growth due to the biased effect of technical change and the change in relative input prices. We refer to this as the rate of induced technical change. A fall in the price of energy, for example, will accelerate the rate of technical change if the bias of technical change is energy using; however if the bias is energy saving it will reduce the rate of technical change. 
Own- and cross-price elasticities are calculated as

$$
\begin{aligned}
\eta_{i j}=\frac{\widehat{\beta}_{i j}+\widehat{S}_{i} \widehat{S}_{j}}{\widehat{S}_{i}}, & \text { for } i \neq j, \\
\eta_{i i}=\frac{\widehat{\beta}_{i i}+\widehat{S}_{i}^{2}-\widehat{S}_{i}}{\widehat{S}_{i}}, & i, j=1, \ldots, n,
\end{aligned}
$$

where all other factor prices and output are fixed while the Morishima elasticities are obtained by using (11).

\subsection{The Generalized Leontief Cost Function}

If we choose the functional form in (4) to be the GL cost function (Diewert and Wales, 1987), we get

$$
C(\mathbf{p}, y, t)=y\left(\sum_{i=1}^{n} \sum_{j=1}^{n} \beta_{i j}\left(p_{i} p_{j}\right)^{\frac{1}{2}}+\sum_{i=1}^{n} \beta_{i t} p_{i} t+\sum_{i=1}^{n} \gamma_{i t} p_{i} t^{2}\right)
$$

where $\beta_{i j}=\beta_{j i}$. Using (5) we get the corresponding optimal input-output demand equations as follows,

$$
a_{i}=\frac{x_{i}}{y}=\sum_{j=1}^{n} \beta_{i j} p_{j}^{\frac{1}{2}} p_{i}^{-\frac{1}{2}}+\beta_{i t} t+\gamma_{i t} t^{2}, \quad i=1, \ldots, n
$$

There is no intercept term in (23) due to the assumption of constant returns to scale and hence all the parameters in (23) can be obtained by estimating only (24). When $i=j$ in (24), $\beta_{i i}$ becomes a constant term in the $i^{\text {th }}$ input-output equation and if $\beta_{i j}=0$ for all $i, j, i \neq j,(24)$ becomes independent of relative input prices and all the cross-price elasticities become zero.

Necessary and sufficient condition for concavity is that the Hessian matrix of (23) 
be negative semi-definite. The elements of the Hessian matrix for (23) are as follows

$$
\begin{aligned}
\mathbf{H}_{i j} & =\frac{1}{2} \beta_{i j}\left(p_{i} p_{j}\right)^{-\frac{1}{2}} & & i \neq j \\
& =-\frac{1}{2} \sum_{j \neq i}^{n} \beta_{i j}\left(p_{j} / p_{i}\right)^{\frac{1}{2}}\left(1 / p_{i}\right) & i & =j .
\end{aligned}
$$

Following Ryan and Wales (2000), we reparametrize equation (23) to impose local concavity. First, we set $\sum_{k=1}^{n} \beta_{i k}=0$ for all $i$, and then we add $\left(\sum_{i=1}^{n} p_{i} d_{i}\right) y$ to the right hand side of (23) which will introduce $n$ new parameters. Therefore, the new set of input-output demand equations are

$$
a_{i}=\frac{x_{i}}{y}=\sum_{j=1}^{n} \beta_{i j} p_{j}^{\frac{1}{2}} p_{i}^{-\frac{1}{2}}+\beta_{i t} t+\gamma_{i t} t^{2}+d_{i} \quad i=1, \ldots, n
$$

Second, we normalize all prices and output to one at the reference point and, as a result, the $i j^{\text {th }}$ element of $\mathbf{H}$ evaluated at this data point becomes

$$
\begin{aligned}
\mathbf{H}_{i j} & =\frac{\beta_{i j}}{2} & i \neq j & \neq j \\
& =-\frac{1}{2} \sum_{j \neq i}^{n} \beta_{i j}=\frac{\beta_{i i}}{2} & i & =j .
\end{aligned}
$$

Finally, we set $\beta_{i j}=-\left(\mathbf{D} \mathbf{D}^{\prime}\right)_{i j}$, where $\left(\mathbf{D D}^{\prime}\right)_{i j}$ is the $i j^{\text {th }}$ element of $\mathbf{D} \mathbf{D}^{\prime}$, and $\mathbf{D}$ is a lower triangular matrix with elements $d_{i j}$ for $i \geq j$ and 0 elsewhere. This gives us the following relationships between $\beta_{i j}$ and $d_{i j}$, in the case of four factors,

$$
\begin{array}{ll}
\beta_{11}=-d_{11}^{2}, & \beta_{12}=-d_{11} d_{21}, \\
\beta_{13}=-d_{11} d_{31}, & \beta_{14}=-d_{11} d_{41}, \\
\beta_{22}=-\left(d_{21}^{2}+d_{22}^{2}\right), & \beta_{23}=-\left(d_{21} d_{31}+d_{22} d_{32}\right), \\
\beta_{24}=-\left(d_{21} d_{41}+d_{22} d_{42}\right), & \beta_{33}=-\left(d_{31}^{2}+d_{32}^{2}+d_{33}^{2}\right), \\
\beta_{34}=-\left(d_{31} d_{41}+d_{32} d_{42}+d_{33} d_{43}\right), & \beta_{44}=-\left(d_{41}^{2}+d_{42}^{2}+d_{43}^{2}+d_{44}^{2}\right) .
\end{array}
$$

Replacing the elements of $\mathbf{B}=\left[\beta_{i j}\right]$ in (26) by the relationships in (28) and estimating 
$d_{i j}$ will guarantee that the estimated GL cost function will be concave at the normalization point and it may also lead to the satisfaction of concavity at other data points in the sample.

For the GL specification we compute the price elasticities as

$$
\begin{array}{rlr}
\eta_{i j} & =\frac{1}{2} \frac{\beta_{i j}\left(p_{i} / p_{j}\right)^{-\frac{1}{2}}}{a_{i}}, & \text { for } i \neq j, \\
\eta_{i i} & =-\frac{1}{2} \frac{\sum_{j \neq i}^{n} \beta_{i j}\left(p_{i} / p_{j}\right)^{-\frac{1}{2}}}{a_{i}} &
\end{array}
$$

The Morishima elasticities are computed using equation (11).

\subsection{The Normalized Quadratic Cost Function}

If we consider the NQ cost function (Diewert and Wales, 1987) in (4), we get

$$
C(\mathbf{p}, y, t)=y\left[\sum_{i=1}^{n} \beta_{i} p_{i}+\frac{1}{2} \frac{\sum_{i=1}^{n} \sum_{j=1}^{n} \beta_{i j} p_{i} p_{j}}{\sum_{i=1}^{n} \theta_{i} p_{i}}+\sum_{i=1}^{n} \beta_{i t} p_{i} t+\sum_{i=1}^{n} \gamma_{i t} p_{i} t^{2}\right]
$$

where $\beta_{i j}=\beta_{j i}$. Equation (31) can be rewritten as

$$
C(\mathbf{p}, y, t)=y\left[\sum_{i=1}^{n} \beta_{i} p_{i}+g(\mathbf{p})+\sum_{i=1}^{n} \beta_{i t} p_{i} t+\sum_{i=1}^{n} \gamma_{i t} p_{i} t^{2}\right]
$$

where $g(\mathbf{p}) \equiv \frac{\mathbf{p}^{\prime} \mathbf{B} \mathbf{p}}{2 \boldsymbol{\theta}^{\prime} \mathbf{p}} . \mathbf{B} \equiv\left[\beta_{i j}\right]$ is a $n \times n$ symmetric matrix, and $\boldsymbol{\theta}=\left[\theta_{1}, \ldots, \theta n\right]>\mathbf{0}$ is a vector of nonnegative constants, not all equal to zero. Usually $\boldsymbol{\theta}$ is predetermined and we set $\theta_{i}$ equal to the sample average values of the respective inputs. In order to identify all of the parameters in the model $n$ extra restrictions on the elements of $\mathbf{B}$ are imposed as

$$
\mathrm{Bp}^{*}=\mathbf{0}
$$

for some chosen $\mathbf{p}^{*}>\mathbf{0}$. 
Application of (5) yields the following system of $n$ equations

$$
\frac{x_{i}}{y}=\beta_{i}+\sum_{j=1}^{n} \beta_{i j} \frac{p_{i}}{\sum_{i=1}^{n} \theta_{i} p_{i}}-\frac{1}{2} \theta_{i}\left(\sum_{i=1}^{n} \sum_{j=1}^{n} \beta_{i j} \frac{p_{i}}{\sum_{i=1}^{n} \theta_{i} p_{i}} \frac{p_{j}}{\sum_{j=1}^{n} \theta_{j} p_{j}}\right)+\beta_{i t} t+\gamma_{i t} t^{2} .
$$

Equation (34) can also be expressed as

$$
\frac{x_{i}}{y}=\beta_{i}+\frac{\sum_{j=1}^{n} \beta_{i j} p_{i}}{\boldsymbol{\theta}^{\prime} \mathbf{p}}-\frac{\theta_{i}}{2} \frac{\mathbf{p}^{\prime} \mathbf{B} \mathbf{p}}{\left(\boldsymbol{\theta}^{\prime} \mathbf{p}\right)^{2}}+\beta_{i t} t+\gamma_{i t} t^{2} .
$$

Furthermore, we assume $\mathbf{p}^{*}=\mathbf{1}_{\mathbf{n}}$ which, in terms of (33), implies $\sum_{j=1}^{n} \beta_{i j}=0$. With these $n$ restrictions on matrix $\mathbf{B}$ and after denoting $w_{i}=\frac{p_{i}}{\sum_{j=1}^{n} \theta_{i} p_{i}}$, the system of factor demand equations (34), in the case of four factors, can be expressed as,

$$
\begin{aligned}
\frac{x_{1}}{y} & =\beta_{11}\left[\left(w_{1}-w_{4}\right)-\frac{\theta_{1}}{2}\left(w_{1}-w_{4}\right)^{2}\right]+\beta_{12}\left[\left(w_{2}-w_{4}\right)-\theta_{1}\left(w_{1}-w_{4}\right)\left(w_{2}-w_{4}\right)\right] \\
& +\beta_{13}\left[\left(w_{3}-w_{4}\right)-\theta_{1}\left(w_{1}-w_{4}\right)\left(w_{3}-w_{4}\right)\right]+\beta_{22}\left[\frac{\theta_{1}}{2}\left(w_{2}-w_{4}\right)^{2}\right] \\
& +\beta_{23}\left[-\theta_{1}\left(w_{2}-w_{4}\right)\left(w_{3}-w_{4}\right)\right]+\beta_{33}\left[-\frac{\theta_{1}}{2}\left(w_{3}-w_{4}\right)^{2}\right]+\beta_{1}+\beta_{1 t} t+\gamma_{1 t} t^{2},(36){ }^{2} \\
\frac{x_{2}}{y}= & \beta_{11}\left[-\frac{\theta_{2}}{2}\left(w_{1}-w_{4}\right)^{2}\right]+\beta_{12}\left[\left(w_{1}-w_{4}\right)-\theta_{2}\left(w_{1}-w_{4}\right)\left(w_{2}-w_{4}\right)\right] \\
+ & \beta_{13}\left[-\theta_{2}\left(w_{1}-w_{4}\right)\left(w_{3}-w_{4}\right)\right]+\beta_{22}\left[\left(w_{2}-w_{4}\right)-\frac{\theta_{2}}{2}\left(w_{2}-w_{4}\right)^{2}\right] \\
+ & \beta_{23}\left[\left(w_{3}-w_{4}\right)-\theta_{2}\left(w_{3}-w_{4}\right)\left(w_{2}-w_{4}\right)\right]+\beta_{33}\left[\frac{\theta_{2}}{2}\left(w_{3}-w_{4}\right)^{2}\right] \\
+ & \beta_{2}+\beta_{2 t} t+\gamma_{2 t} t^{2}, \\
& +\beta_{3}+\beta_{3 t} t+\gamma_{3 t} t^{2}, \\
& +\beta_{13}\left[\left(w_{1}-w_{4}\right)-\theta_{3}\left(w_{1}-w_{4}\right)\left(w_{3}-w_{4}\right)\right]+\beta_{22}\left[\frac{\theta_{3}}{2}\left(w_{2}-w_{4}\right)^{2}\right] \\
& +\beta_{23}\left[\left(w_{2}-w_{4}\right)-\theta_{3}\left(w_{2}-w_{4}\right)\left(w_{3}-w_{4}\right)\right]+\beta_{33}\left[\left(w_{3}-w_{4}\right)-\frac{\theta_{3}}{2}\left(w_{3}-w_{4}\right)^{2}\right] \\
& \left.\left.+w_{4}\right)^{2}\right]+\beta_{12}\left[-\theta_{3}\left(w_{1}-w_{4}\right)\left(w_{2}-w_{4}\right)\right]
\end{aligned}
$$




$$
\begin{aligned}
\frac{x_{4}}{y} & =\beta_{11}\left[-\left(w_{1}-w_{4}\right)-\frac{\theta_{4}}{2}\left(w_{1}-w_{4}\right)^{2}\right]+\beta_{12}\left[-\left(w_{2}-w_{4}\right)-\theta_{4}\left(w_{1}-w_{4}\right)\left(w_{2}-w_{4}\right)\right] \\
& +\beta_{13}\left[-\left(w_{3}-w_{4}\right)-\theta_{4}\left(w_{1}-w_{4}\right)\left(w_{3}-w_{4}\right)\right]+\beta_{22}\left[\left(w_{2}-w_{4}\right)-\frac{\theta_{4}}{2}\left(w_{2}-w_{4}\right)^{2}\right] \\
& +\beta_{23}\left[\left(w_{2}-w_{4}\right)-\left(w_{3}-w_{4}\right)-\theta_{4}\left(w_{1}-w_{4}\right)\left(w_{3}-w_{4}\right)\right] \\
& +\beta_{33}\left[\left(w_{3}-w_{4}\right)-\frac{\theta_{4}}{2}\left(w_{2}-w_{4}\right)^{2}\right]+\beta_{4}+\beta_{4 t} t+\gamma_{4 t} t^{2}
\end{aligned}
$$

Estimates of $\beta_{i}, \beta_{i t}$, and the elements of matrix $\mathbf{B}$, except for the parameters $\beta_{i 4}(i=$ $1,2,3,4)$, are obtained by estimating the system of input-output equations (36)-(39). $\beta_{i 4}$ can then be recovered from the imposed restrictions.

Global concavity for the NQ cost function requires that the estimated $\mathbf{B}$ matrix is negative semidefinite provided that $\boldsymbol{\theta}>\mathbf{0}$ - see Diewert and Wales (1987) for a detailed discussion. However, in empirical applications the estimated $\mathbf{B}$ matrix may not be negative semidefinite and if this turns out to be the case, Diewert and Wales (1987) show that global concavity on the NQ can be imposed without destroying its flexibility by using the technique suggested by Wiley et al. (1973).

To impose global concavity we set

$$
\mathbf{B}=-\mathbf{A} \mathbf{A}^{\prime}
$$

where $\mathbf{A}$ is a lower triangular matrix, with elements $a_{i j}$ for $i \geq j$ and 0 elsewhere, that satisfies

$$
\mathbf{A}^{\prime} \mathbf{p}^{*}=\mathbf{0}_{n}
$$

This gives us the following relationships between $\beta_{i j}$ and $a_{i j}$,

$$
\begin{array}{ll}
\beta_{11}=-a_{11}^{2}, & \beta_{12}=-a_{11} a_{21}, \\
\beta_{13}=-a_{11} a_{31}, & \beta_{22}=-\left(a_{21}^{2}+a_{22}^{2}\right), \\
\beta_{23}=-\left(a_{21} a_{31}+a_{22} a_{32}\right), & \beta_{33}=-\left(a_{31}^{2}+a_{32}^{2}+a_{33}^{2}\right) .
\end{array}
$$

Finally, we replace the elements of $\mathbf{B}$ in the system of input-output equations (36)-(39) 
by the relationships in (40) and estimate $a_{i j}$ which ensures global concavity for the NQ function in (31). This replacement makes the system of input-output equations nonlinear in parameters $a_{i j}$.

For the NQ specification the price elasticities have the following expressions,

$$
\begin{gathered}
\eta_{i i}=\left[\frac{\beta_{i i} \sum_{j=1}^{n} \theta_{j} p_{j}-2 \theta_{i} \sum_{j=1}^{n} \beta_{i j} p_{j}+2 \theta_{i}^{2} g(\mathbf{p})}{\left[\sum_{j=1}^{n} \theta_{j} p_{j}\right]^{2}}\right] \frac{p_{i} y}{x_{i}} \\
\eta_{i j}=\left[\frac{\beta_{i j} \sum_{j=1}^{n} \theta_{j} p_{j}-\theta_{i} \sum_{i=1}^{n} \beta_{i j} p_{j}-\theta_{j} \sum_{j=1}^{n} \beta_{i j} p_{j}+2 \theta_{i} \theta_{j} g(\mathbf{p})}{\left[\sum_{j=1}^{n} \theta_{j} p_{j}\right]^{2}}\right] \frac{p_{j} y}{x_{j}}
\end{gathered}
$$

and the Morishima elasticities can then be computed using (11).

\section{Index Number Techniques}

We also calculate the productivity growth in our sample industries using two widely used index number techniques: the Tornqvist index and the Fisher ideal index. Results from the index number techniques can be used to check the performance of the flexible functional forms. The Tornqvist index is the discrete approximation of equation (1), and the rate of technical change is calculated as follows

$$
\ln y_{t}-\ln y_{t-1}-\sum_{i=1}^{n} \frac{1}{2}\left(s_{i t}+s_{i t-1}\right)\left(\ln x_{i t}-\ln x_{i t-1}\right) .
$$

Equation (43) can also be written as

$$
\ln \prod_{i=1}^{n}\left[\frac{\left(y / x_{i}\right)_{t}}{\left(y / x_{i}\right)_{t-1}}\right]^{\frac{1}{2}\left(s x_{i t}+s x_{i t-1}\right)} .
$$

The advantage of using the Tornqvist index is that it is exact for the linear homogeneous translog aggregator function (see Diewert, 1976a). However, in practice estimates of technical change obtained from the two approaches can be markedly different 
(Slade, 1986, 1989). Obviously one can think of the possibility of using a bilateral Tornqvist index (see Caves et al., 1982) to compare the productivity performances of Canadian and U.S. industries. However, to implement this we require time series data that have been constructed in a consistent way across industries and countries which is not the case with the data sets used in this study. See Keay (2003) for such comparisons between U.S. and Canadian industries and also for the data requirements to do so.

With the Fisher ideal index, first the Fisher ideal quantity index for inputs is calculated as

$$
I^{t}=\left[\frac{\sum_{j=1}^{n} p_{j}^{t} x_{j}^{t}}{\sum_{j=1}^{n} p_{j}^{t} x_{j}^{t-1}} \frac{\sum_{j=1}^{n} p_{j}^{t-1} x_{j}^{t}}{\sum_{j=1}^{n} p_{j}^{t-1} x_{j}^{t-1}}\right]^{1 / 2}
$$

and then the quantity index for the single output is calculated as $Q^{t}=y^{t} / y^{t-1}$. Finally, the Fisher ideal total factor productivity index is computed as

$$
\frac{Q^{t}}{I^{t}}-1
$$

We also obtain a smoothed Fisher ideal index of total factor productivity, following Feng and Serletis (2008), by regressing the raw total factor productivity index on a constant and a time trend, and then calculating the fitted values. ${ }^{6}$

\section{$5 \quad$ Data and Estimation Strategy}

\section{$5.1 \quad$ Data}

In this study we use two different data sets that cover the period from 1961 to 2003 for the Canadian and U.S. manufacturing industries. Data for the Canadian manufacturing industries come from annual Canadian KLEMS database developed by the "Industry Multifactor Productivity Program" of Statistics Canada — see Baldwin et al.

\footnotetext{
${ }^{6}$ TFP estimates obtained from the smoothed Tornqvist index are almost identical to that obtained from the smoothed Fisher ideal index, and are not reported for brevity.
} 
(2007) for a detailed description on the methodology used to construct this database. ${ }^{7}$ Among the Canadian manufacturing industries we consider primary metal (NAICS 331), cement (NAICS 32731), and paper (NAICS 322) manufacturing industries in our sample. ${ }^{8}$ The Canadian KLEMS data set contains annual information on chained Fisher quantity and price indexes for capital, labour, energy, material and services together with the information on quantity index of gross output as well as their nominal values.

The Jorgenson (2008) KLEM database, developed by Dale W. Jorgenson, and described in Jorgenson et al. (2000), provides the sample data for the US manufacturing industries. The database is a combination of industry data collected from the U.S. Bureau of Labor Statistics (BLS) and the U.S. Bureau of Economic Analysis (BEA). It contains information on value and the price of output together with information on the values and prices for four inputs - capital, labour, energy, and material for thirty-five US industries covering the period from 1960 to 2005. The industries generally correspond to the 2-digit sectors in the Standard Industrial Classification (SIC) system. ${ }^{9}$ In this study, we consider two of the thirty-five U.S. manufacturing industries — 'primary metal' and 'paper and allied' — which roughly match with two of the Canadian industries in our sample and we also match the time period with the period covered in the Canadian KLEMS database.

Table 1 provides a summary of descriptive statistics for selected variables in all industries during the study period used in this study. The variables are self-explanatory. Summary statistics include mean and standard deviation of output along with that of

\footnotetext{
${ }^{7}$ Dissou and Ghazal (2010) utilize this dataset to examine energy substitutability in the primary metal and cement industries.

${ }^{8}$ The industries are at the L-level of aggregation in the North American Industry Classification System 2012.

${ }^{9}$ Young (2013), for example, uses this dataset to provide U.S. industry level estimates of the elasticity of substitution between labour and capital. He describes one major desirable feature of the U.S. KLEM database that it includes quality-adjusted labour services that combine data on individuals from the U.S. Census and Current Population Survey (CPS) after controlling for different qualities of labour.
} 
the prices, quantities and cost shares of four inputs. Average annual growth rates of inputs, output, and input prices for all industries are presented in Table 2.

\subsection{Estimation}

For the translog specification, we perform joint estimation of the cost function (12) and the share equations (14) as a system of equations. Error disturbances, $\mathbf{v}_{t}$, which are assumed to have a multivariate normal distribution with zero mean and constant covariance over time are added to the set of equations in the system. We use the iterative Zellner's technique for Seemingly Unrelated Regression (SUR) to estimate the system of equations. However, to avoid the problem of singularity we arbitrary delete the material share equation. Parameter estimates of the deleted material share equation are obtained by using the linear homogeneity and symmetry restrictions.

For the GL and the NQ specifications we only estimate the system of input-output equations (24) and (34), respectively, since the cost functions do not contain any additional information in both cases. All four input-output equations are used for the iterative SUR estimation. In estimating the NQ model for Canadian industries we normalize inputs prices in the first year to one. However, for the U.S. industries normalization is not required as input prices are equal to one for the base year (1996) in the data set.

If estimated models fail to satisfy the curvature condition, we follow the procedures explained in Section 3 to impose concavity. For the translog and the GL models, we follow the route suggested by Ryan and Wales (2000) to impose local concavity. It is important to note that the point of concavity imposition is arbitrary. If imposition of local concavity at all reference points fails to provide the expected concavity coverage at all sample points, then we choose the data point that provides the lowest number of curvature violations as the best approximation point and report results for that. For the NQ model we follow the technique described in Diewert and Wales (1987) to impose global concavity. For all three functional forms, imposing curvature conditions 
transforms the estimating linear system of equations into a nonlinear one in parameters. Thus we use the nonlinear iterative SUR technique to estimate the systems restricted for concavity.

To verify whether the economic theoretical regularity conditions are satisfied by the estimated models we perform checks on positivity, monotonicity, and concavity. We evaluate fitted values of the cost function at each observation as a check for whether the estimated cost function is strictly positive. For monotonicity, we check whether the estimated input demand functions are all strictly positive at all data points. Necessary and sufficient condition for concavity is that the Hessian matrix of the cost function be negative semi-definite, and a real symmetric matrix will be negative semi-definite if it has non-positive eigenvalues. To check for the curvature condition, we compute eigenvalues of the estimated Hessian matrix of the cost function at each point in the sample space.

Although the full basic models are presented in Section 3, we test for the presence of technical change in all three functional forms using the likelihood ratio test. Since constant returns to scale are built in the datasets used in this study, test for the presence of returns to scale is ruled out. Moreover, in the translog model we test for the presence of neutral technical change. Finally, inclusion of the squared term of time trend is also tested for each model.

\section{Result}

\subsection{Theoretical Regularity}

Results from the likelihood ratio tests are presented in Table 3. Possibility of no technical change is rejected at $1 \%$ level of significance for all industries in the sample. In the translog model, the possibility of neutral technical change is also rejected for all industries. However, for the Canadian cement industry in the translog model and for 
the Canadian paper industry in the GL and the NQ models we fail to reject the null hypothesis of no squared time trend at $1 \%$ level of significance.

Tables (4)-(9) present results from estimating the translog, the GL, and the NQ models with and without curvature conditions. All models satisfy positivity and monotonicity at all data points in the sample when curvature conditions are not imposed. However, results for the concavity condition are not quite satisfactory. Counts on the incidence of curvature violations are reported in the tables. When curvature conditions are not imposed only the GL model satisfies concavity at all data points for three out of the five sample industries that we estimate. The translog and the NQ models violate curvature conditions in all cases.

Results from estimating the models with curvature conditions being imposed are also reported in Tables (4)-(9). For the translog and the GL models, imposing curvature conditions does not completely eliminate curvature violations in all cases. For example, in the translog model for the Canadian metal and paper industries and in the GL model for the U.S. metal industry it fails to completely eliminate curvature violations. On the other hand, imposing global curvature conditions on the NQ reduces curvature violations to zero, as expected, in all cases.

Feng and Serletis (2008) find the performances of the translog and the GL models as poor when curvature conditions are being imposed on these models, and since both models fail to meet the curvature condition they do not provide productivity estimates based on these models. In this study, we present a more comprehensive case in the sense that our results include examples where imposing concavity on the translog and the GL models does successfully reduce curvature violations to zero. For example, in both the translog and the GL models for the Canadian cement industry it reduces curvature violations to zero. Moreover, the GL cost function satisfies all regularity conditions even without curvature being imposed for the Canadian metal and paper industries, for example. 
In what follows, we discuss the productivity and elasticity estimates only for those industries where the model satisfies all economic regularity conditions.

\subsection{Productivity Estimates}

Tables (10)-(12) report average total factor productivity measures estimated with all three functional forms used in this paper. With the translog model, for the Canadian cement industry as well as for both U.S. metal and paper industries, imposing curvature restrictions result in the satisfaction of all regularity conditions. However, the difference in TFP estimates, with and without curvature conditions, for these industries are noticeable in Table 10. Moreover, this discrepancy is also present in the estimates of autonomous and biased technical change. Results for the GL model in the case of Canadian cement industry, presented in Table 11, exhibit similar difference in TFP estimates with and without curvature being imposed. It can be seen more vividly in Figure 1 which provides year-by-year TFP estimates for the Canadian cement industry estimated by the GL model with and without curvature being imposed. Given the importance of the rate and biases of technical change it is highly desirable that we get accurate estimates of those parameters.

The NQ model, on the other hand, performs better than the translog and the GL models when curvature condition is being imposed. Average TFP estimates for the NQ model are reported in Table 12. TFP estimates with curvature imposed are almost identical to the ones without curvature being imposed. Year-by-year TFP estimates for this model are presented in Figures 2 and 3. It can be seen that the TFP estimates obtained from the restricted (for curvature) and unrestricted models are almost identical.

Figures 4 and 5 plots year-by-year TFP estimates from the NQ model, together with the productivity measures obtained from the Tornqvist, Fisher, and smoothed Fisher ideal indexes. Estimates from the GL model, when all economic regularity conditions are satisfied without curvature being imposed, are also included. The Tornqvist and 
the Fisher ideal indexes produce similar TFP estimates and for U.S. industries they are virtually identical. Productivity estimates from the NQ and GL models exhibit similar patterns during the sample period. Furthermore, both series of the GL and NQ estimates follow the smoothed Fisher ideal index very closely. Feng and Serletis (2008) use this criterion in evaluating the performance of NQ and AIM functional forms in providing TFP estimates. However, there is no theoretical correspondence of the smoothed Fisher Ideal index with the NQ or the AIM functional forms, although the correspondence between the Tornqvist index and the translog functional forms is well known (Diewert, 1976b). If we consider the benchmark adopted by Feng and Serletis (2008), both the NQ (with curvature being imposed) and the GL (without curvature being imposed) functional forms perform equally well in providing TFP estimates.

\subsection{Elasticity Estimates}

Tables (13)-(16) present own and cross price elasticities of factor demand along with the Morishima elasticities for our sample industries in U.S. and Canada. We calculate elasticities at the middle year of the sample period. Although not reported here for brevity, we also compute the elasticities when curvature conditions are not imposed. In most of the cases they follow closely to the ones reported in the tables. In general, elasticity estimates obtained from the NQ model are smaller in absolute terms than the ones obtained from the GL and translog models.

Estimated own price elasticities of demand in all cases have the correct sign. For all industries in the sample we find the derived factor demands inelastic as the estimated own price elasticities are below one in absolute terms. However, one particular feature of the own price elasticity estimates from the GL and the NQ models is worth mentioning. Feng and Serletis (2008) find that own price elasticity estimates in the NQ model for U.S. manufacturing do not show variations over time and Diewert and Lawrence (2002), who first identified the issue, term this as 'the problem of trending elasticities'. However, our findings on own price elasticities for our sample industries 
do not show any lack of variation, and more interestingly they show more variation than the ones we estimate with the GL model. Figure 6 plots the own price elasticities for the U.S. paper industry, for example.

Estimates for the Morishima elasticities of substitution are mostly positive for all pairs of inputs in all industries. This suggests that the inputs are mostly substitutes in all industries. However, few exceptions are worth mentioning. For example, estimates of $\sigma_{M K}^{m}$ in the Canadian cement industry and $\sigma_{L K}^{m}$ and $\sigma_{K L}^{m}$ in the U.S. metal and paper industries, respectively, are negative in the NQ model while they are positive in the GL model.

\section{Conclusion}

In this paper we provide an empirical comparison and evaluation of three widely used locally flexible cost functional forms - the translog, the GL, and the NQ - in providing TFP estimates once they satisfy the economic theoretic regularity conditions. In doing so, we take the econometric approach to productivity measurement and generate estimates of total factor productivity for two U.S. industries - primary metal and paper - along with three Canadian industries — primary metal, cement, and paper — covering the period of 1961 to 2003. Moreover, we impose curvature restrictions on the functional forms once the estimated models fail to satisfy the curvature condition. In particular, for the translog and the GL models we impose local concavity according to the way suggested by Ryan and Wales (2000) while for the NQ model we impose global concavity following the route suggested by Diewert and Wales (1987).

Estimation results for the sample industries provide us the opportunity to cover all possible cases one might encounter in terms of curvature violations while estimating these three locally flexible functional forms: (i) curvature conditions are satisfied without curvature restrictions being imposed, (ii) curvature conditions are satisfied when curvature restrictions are imposed, and (iii) curvature conditions are not sat- 
isfied even with curvature restrictions being imposed. Findings reveal evidences of concavity violations even with curvature being imposed locally for the translog and the GL models. However, curvature violations reduce to zero for the NQ model when concavity is imposed globally.

When all economic regularity conditions are satisfied with curvature being imposed, our results suggest that the NQ model performs better than the other two models in providing TFP estimates. Estimates of productivity from the unrestricted and the restricted NQ models are almost identical. However, the GL cost function performs equally well when all the regularity conditions are satisfied without curvature being imposed. Based on the evidences provided in this study we argue that since desired curvature coverage is not guaranteed in the translog and the GL models and local curvature imposition on these functional forms affects the productivity estimates, functional forms with global curvature conditions appear to be a better choice for econometric productivity estimation. 


\section{References}

Acemoglu, Daron, "Directed Technical Change," Review of Economic Studies, 2002a, $69(4), 781-810$.

_ , "Technical Change, Inequality, and the Labor Market," Journal of Economic Literature, 2002b, 40 (1), 7-72.

_ , "Equilibrium Bias of Technology," Econometrica, 2007, 75 (5), 1371-1410.

Baldwin, John R, Wulong Gu, and Beiling Yan, "User Guide for Statistics Canada's Annual Multifactor Productivity Program," Canadian Productivity Review Research Paper, Statistics Canada, Catalogue no. 15-206-XIE 2007.

Barnett, William A and Apostolos Serletis, "Consumer Preferences and Demand Systems," Journal of Econometrics, 2008, 147 (2), 210-224.

Berndt, Ernst R, The Practice of Econometrics: Classics and Contemporary, Addison-Wesley Publishing Company, 1991.

Biesebroeck, J Van, "Robustness of Productivity Estimates," Journal of Industrial Economics, 2007, 55 (3), 529-569.

Binswanger, Hans P, "A Cost Function Approach to the Measurement of Elasticities of Factor Demand and Elasticities of Substitution," American Journal of Agricultural Economics, 1974a, 56 (2), 377-386.

_ , "The Measurement of Technical Change Biases with Many Factors of Production," American Economic Review, 1974b, 64 (6), 964-976.

Blackorby, Charles and R Robert Russell, "Will the Real Elasticity of Substitution Please Stand Up? (A Comparison of the Allen/Uzawa and Morishima Elasticities)," American Economic Review, 1989, 79 (4), 882-888. 
Caves, Douglas W, Laurits R Christensen, and Joseph A Swanson, "Productivity in US railroads, 1951-1974," Bell Journal of Economics, 1980, 11 (1), 166-181.

_, _, and W Erwin Diewert, "Multilateral Comparisons of Output, Input, and Productivity Using Superlative Index Numbers," The Economic Journal, 1982, 92 (365), 73-86.

Chalfant, James A and Nancy E Wallace, "Bayesian analysis and regularity conditions on flexible functional forms: application to the US motor carrier industry," in W E Griffiths, H Lutkepohl, and M E Bock, eds., Readings in Econometric Theory and Practice: A Volume in Honor of George Judge, Amsterdam: North-Holland, 1992.

Christensen, Laurits R, Dale W Jorgenson, and Lawrence J Lau, "Conjugate Duality and the Transcendental Logarithmic Production Function," Econometrica, 1971, 39 (4), 255-256.

_, _, and _ , "Transcendental Logarithmic Production Frontiers," Review of Economics and Statistics, 1973, 55 (1), 28-45.

Delorme, Francois and John Lester, "The Structure of Production in Ten Canadian Industries," Empirical Economics, 1990, 15 (4), 315-346.

Diewert, W. Erwin, "Exact and Superlative Index Numbers," Journal of Econometrics, 1976, 4 (2), 115-145.

Diewert, W Erwin, "Exact and Superlative Index Numbers," Journal of econometrics, 1976, 4 (2), 115-145.

- and Denis Lawrence, The Deadweight Costs of Capital Taxation in Australia, Springer, 2002.

_ and Terence J Wales, "Flexible Functional Forms and Global Curvature Conditions," Econometrica, 1987, 55 (1), 43-68. 
Dissou, Yazid and Reza Ghazal, "Energy Substitutability in Canadian Manufacturing Econometric Estimation with Bootstrap Confidence Intervals," Energy Journal, 2010, 31 (1), 121-148.

Feng, Guohua and Apostolos Serletis, "Productivity Trends in US Manufacturing: Evidence from the NQ and AIM Cost Functions," Journal of Econometrics, 2008, 142 (1), 281-311.

Fisher, Douglas, Adrian R Fleissig, and Apostolos Serletis, "An Empirical Comparison of Flexible Demand System Functional Forms," Journal of Applied Econometrics, 2001, 16 (1), 59-80.

Gallant, A Ronald and Gene H Golub, "Imposing Curvature Restrictions on Flexible Functional Forms," Journal of Econometrics, 1984, 26 (3), 295-321.

Geweke, John, "Exact Inference in the Inequality Constrained Normal Linear Regression Model," Journal of Applied Econometrics, 1986, 1 (2), 127-141.

Griffiths, William E, Christopher J O'Donnell, and Agustina Tan Cruz, "Imposing Regularity Conditions on a System of Cost and Factor Share Equations," Australian Journal of Agricultural and Resource Economics, 2000, 44 (1), 107-127.

Hulten, Charles R, "Total Factor Productivity: A Short Biography," in C R Hulten, E R Dean, and M J Harper, eds., New Developments in Productivity Analysis, University of Chicago Press, 2001, pp. 1-54. http://www.nber.org/chapters/c10122.

Jaffe, Adam B, Richard G Newell, and Robert N Stavins, "Technological change and the Environment," Handbook of Environmental Economics, 2003, 1, 461516.

Jin, Hui and Dale W Jorgenson, "Econometric Modeling of Technical Change," Journal of Econometrics, 2010, 157 (2), 205-219. 
Jorgenson, Dale W., "35 Sector KLEM," Harvard Dataverse, V1, http://hdl. handle.net/1902.1/10684, 2008.

Jorgenson, Dale W, Kevin J Stiroh, Robert J Gordon, and Daniel E Sichel, "Raising the Speed Limit: US Economic Growth in the Information Age," Brookings Papers on Economic Activity, 2000, pp. 125-235.

Keay, Ian, "Who is to Blame? Canadian Manufacturers and the Absence of Income Per Capita Convergence," Review of Economics and Statistics, 2003, 85 (1), 166-177.

Kohli, Ulrich, "Production, Foreign Trade, and Global Curvature Conditions: Switzerland, 1948-1988," Swiss Journal of Economics and Statistics, 1992, 128 (1), $3-20$.

Lau, Lawrence J, "Testing and Imposing Monotonicity, Convexity and Quasiconvexity Constraints," in Melvyn Fuss and D. McFadden, eds., Production Economics: A Dual Approach to Theory and Applications, Vol. 1, Amsterdam: North Holland, 1978, pp. 409-453.

León-Ledesma, Miguel A, Peter McAdam, and Alpo Willman, "Identifying the Elasticity of Substitution with Biased Technical Change," American Economic Review, 2010, 100 (4), 1330-1357.

Morey, Edward R, "An Introduction to Checking, Testing, and Imposing Curvature Properties: The True Function and The Estimated Function," Canadian Journal of Economics, 1986, 19 (2), 207-235.

Moschini, Giancarlo, "Imposing Local Curvature Conditions in Flexible Demand Systems," Journal of Business and Economic Statistics, 1999, 17 (4), 487-490.

Norsworthy, J Randolph, "Growth Accounting and Productivity Measurement," Review of Income and Wealth, 1984, 30 (3), 309-329. 
Ryan, David L and Terence J Wales, "A Simple Method for Imposing Local Curvature in Some Flexible Consumer-Demand Systems," Journal of Business and Economic Statistics, 1998, 16 (3), 331-338.

_ and _ , "Imposing Local Concavity in the Translog and Generalized Leontief Cost Functions," Economics Letters, 2000, 67 (3), 253-260.

Slade, Margaret E, "Total-factor-productivity Measurement When Equilibrium is Temporary: A Monte Carlo Assessment," Journal of Econometrics, 1986, 33 (1), 75-95.

_, "Modelling Stochastic and Cyclical Components of Technical Change: An Application of the Kalman Filter," Journal of Econometrics, 1989, 41 (3), 363-383.

Terrell, Dek, "Incorporating Monotonicity and Concavity Conditions in Flexible Functional Forms," Journal of Applied Econometrics, 1996, 11 (2), 179-194.

Wiley, David E, William H Schmidt, and William J Bramble, "Studies of a Class of Covariance Structure Models," Journal of the American statistical association, 1973, 68 (342), 317-323.

Wills, John, "Technical Change in the US Primary Metals Industry," Journal of Econometrics, 1979, 10 (1), 85-98.

Young, Andrew T, "US Elasticities of Substitution and Factor Augmentation at the Industry Level," Macroeconomic Dynamics, 2013, 17 (04), 861-897. 
Table 1: Summary Statistics: Mean and Standard Deviation (in parenthesis): 1961-2003

\begin{tabular}{|c|c|c|c|c|c|}
\hline \multirow[b]{2}{*}{ Variables } & \multicolumn{3}{|c|}{ Canada } & \multicolumn{2}{|c|}{ US } \\
\hline & Cement & Metal & Paper & Metal & Paper \\
\hline Price of Capital & $37.29(29.13)$ & $35.77(28.56)$ & $54.40(42.17)$ & $0.58(0.28)$ & $0.61(0.27)$ \\
\hline Price of Labour & $51.30(30.81)$ & $52.29(34.15)$ & $50.10(32.28)$ & $0.64(0.34)$ & $0.63(0.37)$ \\
\hline Price of Material & $57.20(31.25)$ & $60.11(30.34)$ & $58.72(31.15)$ & $0.67(0.30)$ & $0.63(0.31)$ \\
\hline Price of Energy & $46.81(33.20)$ & $55.85(34.74)$ & $44.98(33.31)$ & $0.65(0.35)$ & $0.64(0.36)$ \\
\hline Quantity of Capital & $96.78(15.37)$ & $84.44(20.75)$ & $90.39(30.60)$ & $18137.85(2594.18)$ & $16793.13(6717.58)$ \\
\hline Quantity of Labour & $82.92(11.11)$ & $101.51(10.97)$ & 102.34 (18.79) & $39062.33(8707.00)$ & $32187.82(3843.13)$ \\
\hline Quantity of Material & $59.43(16.16)$ & $60.97(20.66)$ & $63.14(23.86)$ & $106246.30(14826.51)$ & $68784.46(18347.83)$ \\
\hline Quantity of Energy & $110.56(26.27)$ & $86.40(16.93)$ & $92.01(14.18)$ & $11827.48(2643.29)$ & $5770.94(1017.06)$ \\
\hline Cost Share of Capital & $17.54(3.17)$ & $9.03(2.97)$ & $16.08(6.08)$ & $9.52(1.52)$ & $13.29(1.70)$ \\
\hline Cost Share of Labour & $24.38(1.54)$ & $20.16(2.52)$ & $22.67(3.53)$ & $20.86(1.47)$ & $25.55(1.89)$ \\
\hline Cost Share of Material & $51.17(2.39)$ & $63.00(1.84)$ & $51.97(3.40)$ & $63.38(1.08)$ & $56.57(1.33)$ \\
\hline Cost Share of Energy & $6.91(1.18)$ & $7.81(1.57)$ & $9.27(2.00)$ & $6.24(1.25)$ & $4.59(0.96)$ \\
\hline Output & $65.99(15.20)$ & $64.08(19.21)$ & $71.78(19.44)$ & $172455.70(24263.58)$ & $123955(32039.78)$ \\
\hline
\end{tabular}

Notes: Sample period, annual data 1961-2003 $(T=43)$. 
Table 2: Average Annual Growth Rates: 1961-2003

\begin{tabular}{lccccc}
\hline & \multicolumn{3}{c}{ Canada } & \multicolumn{2}{c}{ US } \\
\cline { 2 - 6 } Variables & Cement & Metal & Paper & Metal & Paper \\
\hline Price of Capital & 5.80 & 4.63 & 2.10 & 3.62 & 2.14 \\
Price of Labour & 5.30 & 5.42 & 5.45 & 4.42 & 5.13 \\
Price of Material & 4.20 & 3.94 & 4.00 & 3.34 & 3.54 \\
Price of Energy & 6.37 & 5.40 & 6.59 & 4.37 & 4.54 \\
Quantity of Capital & 0.94 & 1.79 & 2.09 & 1.00 & 3.11 \\
Quantity of Labour & 1.56 & 0.68 & 1.15 & -.52 & 0.81 \\
Quantity of Material & 3.04 & 2.96 & 3.21 & 0.50 & 1.94 \\
Quantity of Energy & 0.20 & 1.58 & 1.11 & -.13 & 1.15 \\
Output & 2.67 & 2.72 & 2.31 & 0.61 & 2.09 \\
\hline
\end{tabular}

Notes: Sample period, annual data 1961-2003 $(T=43)$.

Table 3: Test Statistics for Likelihood Ratio Tests

\begin{tabular}{lrrrrr}
\hline & \multicolumn{3}{c}{ Canada } & \multicolumn{2}{c}{ US } \\
\cline { 2 - 6 } Functional Form & Cement & Metal & Paper & Metal & Paper \\
\hline No Technical Change & & & & & \\
TL & 72.62 & 152.39 & 127.12 & 77.63 & 160.88 \\
GL & 124.84 & 185.23 & 179.20 & 101.04 & 248.86 \\
NQ & 138.10 & 160.68 & 200.64 & 105.23 & 206.22 \\
\hline No Squared Term of Time & & & & \\
TL & $2.17^{*}$ & 42.13 & 8.71 & 33.91 & 28.64 \\
GL & 22.23 & 45.00 & $11.80^{*}$ & 66.53 & 97.00 \\
NQ & 29.76 & 44.68 & $10.85^{*}$ & 62.43 & 92.39 \\
\hline Neutral Technical Change & & & & \\
TL & 15.12 & 78.82 & 78.56 & 52.24 & 117.85 \\
\hline
\end{tabular}

Notes: Test for the possibility of no technical change involves five restrictions in the translog, $\beta_{t}=\beta_{t t}=\beta_{i t}=0$, for $i=1, \ldots, n-1$, and eight restrictions in both the GL and the NQ models, $\beta_{i t}=\gamma_{i t}=0$, for $i=1, \ldots, n$. Test for the possibility of neutral technical change in the translog imposes three restrictions, $\beta_{i t}=0$, for $i=1, \ldots, n-1$. Again, test for the inclusion of squared time trend involves one parameter restriction in the translog, $\beta_{t t}=0$, and in both the GL and the NQ models it involves four restrictions, $\gamma_{i t}=0$, for $i=1, \ldots, n$. In all cases, prob $>\chi^{2}=0.0000$ except for the cases identified with * For the Canadian Paper industry, in case of GL prob $>\chi^{2}=0.0189$, and in case of NQ prob $>\chi^{2}=0.0283$, while for the Canadian Cement industry, in TL prob $>\chi^{2}=0.1406$. 
Table 4: Translog Parameter Estimates For Canadian Industries

\begin{tabular}{|c|c|c|c|c|c|c|}
\hline \multirow[b]{2}{*}{ Parameter } & \multicolumn{2}{|c|}{ Cement } & \multicolumn{2}{|c|}{ Metal } & \multicolumn{2}{|c|}{ Paper } \\
\hline & $\begin{array}{c}\text { Curvature } \\
\text { Not Imposed }\end{array}$ & $\begin{array}{l}\text { Local Curvature } \\
\text { Imposed }\end{array}$ & $\begin{array}{c}\text { Curvature } \\
\text { Not Imposed }\end{array}$ & $\begin{array}{l}\text { Local Curvature } \\
\text { Imposed }\end{array}$ & $\begin{array}{c}\text { Curvature } \\
\text { Not Imposed }\end{array}$ & $\begin{array}{l}\text { Local Curvature } \\
\text { Imposed }\end{array}$ \\
\hline$\beta_{0}$ & $-.2068(.012)$ & $2.7101(.009)$ & $1.6140(.014)$ & $4.6604(.005)$ & $1.1430(.015)$ & $5.6763(.017)$ \\
\hline$\beta_{k}$ & $.2133(.007)$ & $.2121(.002)$ & $.1001(.003)$ & $.0938(.002)$ & $.1498(.007)$ & $.2133(.012)$ \\
\hline$\beta_{l}$ & $.2238(.007)$ & $.2453(.002)$ & $.2792(.009)$ & $.2041(.002)$ & $.3800(.010)$ & $.1632(.004)$ \\
\hline$\beta_{e}$ & $.0857(.006)$ & $.0492(.001)$ & $.1056(.006)$ & $.0582(.001)$ & $.1244(.007)$ & .0997 (.003) \\
\hline$\beta_{k k}$ & $.0815(.006)$ & - & $.0441(.002)$ & - & $.0765(.004)$ & - \\
\hline$\beta_{l l}$ & $.0919(.013)$ & - & $.0842(.012)$ & - & $.1943(.015)$ & - \\
\hline$\beta_{e e}$ & $.0486(.004)$ & - & $.0493(.006)$ & - & $.0495(.005)$ & - \\
\hline$\beta_{k l}$ & $-.0402(.003)$ & - & $-.0223(.002)$ & - & $-.0234(.001)$ & - \\
\hline$\beta_{k e}$ & $-.0270(.003)$ & 一 & $-.0057(.002)$ & - & $-.0119(.001)$ & - \\
\hline$\beta_{l e}$ & $-.0304(.005)$ & - & $.0190(.005)$ & - & $-.0013(.004)$ & - \\
\hline$\beta_{k t}$ & $-.0006(.000)$ & $-.0006(.000)$ & $.0006(.000)$ & $.0006(.000)$ & $.0006(.000)$ & $.0007(.000)$ \\
\hline$\beta_{l t}$ & $.0001(.000)$ & $.0001(.000)$ & $-.0029(.000)$ & $-.0028(.000)$ & $-.0049(.000)$ & $-.0039(.000)$ \\
\hline$\beta_{e t}$ & $-.0007(.000)$ & $-.0007(.000)$ & $-.0007(.000)$ & $-.0006(.000)$ & $-.0004(.000)$ & $-.0004(.000)$ \\
\hline$\beta_{t}$ & $-.0044(.000)$ & $-.0035(.000)$ & $.0077(.001)$ & $.0024(.001)$ & $-.0003(.001)$ & $-.0069(.001)$ \\
\hline$\beta_{t t}$ & - & - & $-.0007(.000)$ & $-.0007(.000)$ & $-.0002(.000)$ & $-.0002(.000)$ \\
\hline$a_{k k}$ & - & $.2903(.009)$ & - & $.2019(.006)$ & - & $.3028(.018)$ \\
\hline$a_{k l}$ & - & $-.0303(.012)$ & - & $.0191(.008)$ & - & $-.0297(.016)$ \\
\hline$a_{l l}$ & - & $.3222(.019)$ & - & $-.2968(.019)$ & - & $.0618(.018)$ \\
\hline$a_{k e}$ & - & $.0508(.009)$ & - & $.0038(.009)$ & - & $-.0310(.006)$ \\
\hline$a_{l e}$ & - & $.0436(.013)$ & - & $.1097(.015)$ & - & $-.1983(.015)$ \\
\hline$a_{e e}$ & - & $-.0000(2.02)$ & - & $-.0000(8.28)$ & - & $-.0001(.000)$ \\
\hline Curvature Violations & 11 & 0 & 15 & 3 & 43 & 3 \\
\hline Log likelihood & 537.62 & 537.14 & 545.05 & 543.20 & 522.56 & 517.63 \\
\hline
\end{tabular}

Notes: Sample period, annual data 1961-2003 $(T=43)$. Standard errors of the parameter estimates are reported in parenthesis. Positivity and monotonicity violations are 0 in each case. 
Table 5: Translog Parameter Estimates For US Industries

\begin{tabular}{lcccc}
\hline \multirow{2}{*}{ Parameter } & \multicolumn{2}{c}{ Metal } & \multicolumn{2}{c}{ Paper } \\
\cline { 2 - 5 } & $\begin{array}{c}\text { Curvature } \\
\text { Not Imposed }\end{array}$ & $\begin{array}{c}\text { Local Curvature } \\
\text { Imposed }\end{array}$ & $\begin{array}{c}\text { Curvature } \\
\text { Not Imposed }\end{array}$ & $\begin{array}{c}\text { Local Curvature } \\
\text { Imposed }\end{array}$ \\
\hline$\beta_{0}$ & $-.0464(.012)$ & $.0141(.007)$ & $.1181(.010)$ & $.0368(.006)$ \\
$\beta_{k}$ & $.0779(.003)$ & $.0712(.002)$ & $.0827(.002)$ & $.1047(.001)$ \\
$\beta_{l}$ & $.2580(.010)$ & $.2649(.005)$ & $.2755(.009)$ & $.2963(.004)$ \\
$\beta_{e}$ & $.0704(.003)$ & $.0669(.002)$ & $.0648(.002)$ & $.0564(.001)$ \\
$\beta_{k k}$ & $.0403(.004)$ & - & $.0770(.004)$ & - \\
$\beta_{l l}$ & $.1851(.035)$ & - & $-.0183(.026)$ & - \\
$\beta_{e e}$ & $.0684(.006)$ & - & $.0406(.003)$ & - \\
$\beta_{k l}$ & $.0022(.006)$ & - & $.0616(.007)$ & - \\
$\beta_{k e}$ & $-.0223(.003)$ & - & $-.0116(.002)$ & - \\
$\beta_{l e}$ & $-.0466(.011)$ & - & $.0098(.007)$ & - \\
$\beta_{k t}$ & $.0009(.000)$ & $.0007(.000)$ & $.0020(.000)$ & $.0017(.000)$ \\
$\beta_{l t}$ & $-.0017(.000)$ & $-.0020(.000)$ & $-.0009(.000)$ & $-.0012(.000)$ \\
$\beta_{e t}$ & $-.0003(.000)$ & $-.0004(.000)$ & $-.0007(.000)$ & $-.0008(.000)$ \\
$\beta_{t}$ & $.0113(.001)$ & $.0063(.001)$ & $-.0116(.000)$ & $-.0086(.001)$ \\
$\beta_{t t}$ & $-.0006(.000)$ & $-.0005(.000)$ & $.0004(.000)$ & $.0005(.000)$ \\
$a_{k k}$ & - & $.1984(.007)$ & - & $.1830(.009)$ \\
$a_{k l}$ & - & $-.1266(.045)$ & - & $.1167(.036)$ \\
$a_{l l}$ & - & $.1705(.123)$ & - & $.4347(.033)$ \\
$a_{k e}$ & - & $.1239(.022)$ & - & $.0324(.014)$ \\
$a_{l e}$ & - & $.0039(.072)$ & - & $-.0816(.020)$ \\
$a_{e e}$ & - & $.0000(3.56)$ & - & $-0000(5.67)$ \\
\hline Curvature Violations & 28 & 0 & & - \\
Log likelihood & 562.45 & 546.48 & 603.30 & 589.67 \\
\hline & - & - & - & - \\
\hline
\end{tabular}

Notes: Sample period, annual data 1961-2003 $(T=43)$. Standard errors of the parameter estimates are reported in parenthesis. Positivity and monotonicity violations are 0 in each case. 
Table 6: GL Parameter Estimates For Canadian Industries

\begin{tabular}{|c|c|c|c|c|}
\hline \multirow[b]{2}{*}{ Parameter } & \multicolumn{2}{|c|}{ Cement } & \multirow{2}{*}{$\begin{array}{c}\text { Metal } \\
\text { Curvature } \\
\text { Not Imposed }\end{array}$} & \multirow{2}{*}{$\begin{array}{c}\text { Paper } \\
\text { Curvature } \\
\text { Not Imposed }\end{array}$} \\
\hline & $\begin{array}{c}\text { Curvature } \\
\text { Not Imposed }\end{array}$ & $\begin{array}{c}\text { Local Curvature } \\
\text { Imposed }\end{array}$ & & \\
\hline$\beta_{k l}$ & $-.1861(.048)$ & - & $-.0830(.038)$ & $-.0258(.011)$ \\
\hline$\beta_{k m}$ & $-.2340(.102)$ & - & $.0770(.022)$ & $.0635(.009)$ \\
\hline$\beta_{k e}$ & $.6909(.103)$ & - & $.1511(.055)$ & $.0238(.024)$ \\
\hline$\beta_{k t}$ & $-.0191(.007)$ & -.0269 (.009) & $.0204(.005)$ & $.0036(.002)$ \\
\hline$\gamma_{k t}$ & $-.0002(.000)$ & $.0000(.000)$ & $-.0006(.000)$ & - \\
\hline$\beta_{k k}$ & $1.8184(.124)$ & - & $1.0591(.050)$ & $1.0982(.053)$ \\
\hline$\beta_{l m}$ & $1.5267(.150)$ & - & $-.0224(.062)$ & $-.0072(.069)$ \\
\hline$\beta_{l e}$ & $-.0576(.081)$ & - & $.4923(.086)$ & $.4384(.034)$ \\
\hline$\beta_{l t}$ & $-.0040(.003)$ & $-.0273(.004)$ & $-.0125(.004)$ & $-.0164(.001)$ \\
\hline$\gamma_{l t}$ & $.0000(.000)$ & $.0003(.000)$ & $-.0004(.000)$ & - \\
\hline$\beta_{l l}$ & $-.0948(.181)$ & - & $1.8487(.103)$ & $1.4791(.096)$ \\
\hline$\beta_{m e}$ & $.0524(.164)$ & - & $.2914(.050)$ & $.1117(.038)$ \\
\hline$\beta_{m t}$ & $-.0267(.004)$ & $-.0135(.002)$ & $.0063(.001)$ & $.0069(.000)$ \\
\hline$\gamma_{m t}$ & $.0006(.000)$ & $.0004(.000)$ & $-.0001(.000)$ & - \\
\hline$\beta_{m m}$ & $-.1489(.170)$ & — & $.5685(.051)$ & $.5582(.055)$ \\
\hline$\beta_{e t}$ & $-.0241(.009)$ & $-.0283(.008)$ & $.0237(.008)$ & $-.0128(.001)$ \\
\hline$\gamma_{e t}$ & $-.0002(.000)$ & $-.0001(.000)$ & $-.0007(.000)$ & - \\
\hline$\beta_{e e}$ & $1.7650(.302)$ & - & $.4530(.183)$ & $.9523(.116)$ \\
\hline$d_{k}$ & - & $1.8569(.094)$ & - & - \\
\hline$d_{k k}$ & - & $.5854(.069)$ & - & - \\
\hline$d_{k m}$ & - & $.1858(.099)$ & - & - \\
\hline$d_{k l}$ & - & $.1396(.116)$ & - & - \\
\hline$d_{l}$ & - & $1.6205(.033)$ & - & - \\
\hline$d_{l l}$ & - & $.3011(.325)$ & 一 & - \\
\hline$d_{l m}$ & - & $.1178(.176)$ & 一 & - \\
\hline$d_{m}$ & - & $.9087(.023)$ & - & - \\
\hline$d_{m m}$ & - & $.0008(.089)$ & - & - \\
\hline$d_{e}$ & - & $2.7003(.065)$ & - & - \\
\hline Curvature Violations & 43 & 0 & 0 & 0 \\
\hline Log likelihood & 184.88 & 184.48 & 237.95 & 280.0 \\
\hline
\end{tabular}

Notes: Sample period, annual data 1961-2003 $(T=43)$. Standard errors of the parameter estimates are reported in parenthesis. Positivity and monotonicity violations are 0 in each case. 
Table 7: GL Parameter Estimates For US Industries

\begin{tabular}{|c|c|c|c|}
\hline \multirow[b]{2}{*}{ Parameter } & \multicolumn{2}{|c|}{ Metal } & \multirow{2}{*}{$\begin{array}{c}\text { Paper } \\
\text { Curvature } \\
\text { Not Imposed }\end{array}$} \\
\hline & $\begin{array}{c}\text { Curvature } \\
\text { Not Imposed } \\
\end{array}$ & $\begin{array}{c}\text { Local Curvature } \\
\text { Imposed }\end{array}$ & \\
\hline$\beta_{k l}$ & $-.0145(.021)$ & - & $-.0632(.012)$ \\
\hline$\beta_{k m}$ & $.1269(.019)$ & - & $.1379(.017)$ \\
\hline$\beta_{k e}$ & $-.0013(.007)$ & - & $-.0074(.005)$ \\
\hline$\beta_{k t}$ & $.0007(.000)$ & $.0007(.001)$ & $.0009(.000)$ \\
\hline$\gamma_{k t}$ & $.0000(.000)$ & $.0000(.000)$ & $.0000(.000)$ \\
\hline$\beta_{k k}$ & $-.0305(.011)$ & - & $.0293(.007)$ \\
\hline$\beta_{l m}$ & $.2917(.069)$ & - & $.2533(.042)$ \\
\hline$\beta_{l e}$ & $.0195(.020)$ & - & $.0128(.011)$ \\
\hline$\beta_{l t}$ & $-.0019(.001)$ & $-.0040(.001)$ & $-.0096(.000)$ \\
\hline$\gamma_{l t}$ & $.0001(.000)$ & $.0000(.000)$ & $.0002(.000)$ \\
\hline$\beta_{l l}$ & $-.0535(.078)$ & - & $.1770(.043)$ \\
\hline$\beta_{m e}$ & $-.0304(.023)$ & - & $.0068(.014)$ \\
\hline$\beta_{m t}$ & $.0092(.001)$ & $.0073(.001)$ & $.0028(.001)$ \\
\hline$\gamma_{m t}$ & $-.0002(.000)$ & $-.0002(.000)$ & $-.0001(.000)$ \\
\hline$\beta_{m m}$ & $.1846(.077)$ & - & $.1504(.053)$ \\
\hline$\beta_{e t}$ & $.0016(.000)$ & $.0019(.000)$ & $.0003(.000)$ \\
\hline$\gamma_{e t}$ & $-.0001(.000)$ & $-.0001(.000)$ & $-.0001(.000)$ \\
\hline$\beta_{e e}$ & $.0803(.013)$ & - & $.0410(.008)$ \\
\hline$d_{k}$ & - & $.0648(.004)$ & - \\
\hline$d_{k k}$ & - & $.3086(.019)$ & - \\
\hline$d_{k m}$ & - & $-.2921(.077)$ & - \\
\hline$d_{k l}$ & - & $-.0371(.080)$ & - \\
\hline$d_{l}$ & - & $.2915(.008)$ & - \\
\hline$d_{l l}$ & - & $-.2079(.058)$ & - \\
\hline$d_{l m}$ & - & $.2246(.063)$ & - \\
\hline$d_{m}$ & - & $.5688(.008)$ & - \\
\hline$d_{m m}$ & - & $.0001(.564)$ & - \\
\hline$d_{e}$ & - & $.0603(.001)$ & - \\
\hline Curvature Violations & 43 & 1 & 0 \\
\hline Log likelihood & 561.69 & 561.39 & 644.86 \\
\hline
\end{tabular}

Notes: Sample period, annual data 1961-2003 $(T=43)$. Standard errors of the parameter estimates are reported in parenthesis. Positivity and monotonicity violations are 0 in each case. 
Table 8: NQ Estimates For Canadian Industries

\begin{tabular}{|c|c|c|c|c|c|c|}
\hline \multirow[b]{2}{*}{ Parameter } & \multicolumn{2}{|c|}{ Cement } & \multicolumn{2}{|c|}{ Metal } & \multicolumn{2}{|c|}{ Paper } \\
\hline & $\begin{array}{c}\text { Curvature } \\
\text { Not Imposed }\end{array}$ & $\begin{array}{c}\text { Global Curvature } \\
\text { Imposed }\end{array}$ & $\begin{array}{c}\text { Curvature } \\
\text { Not Imposed }\end{array}$ & $\begin{array}{c}\text { Global Curvature } \\
\text { Imposed }\end{array}$ & $\begin{array}{c}\text { Curvature } \\
\text { Not Imposed }\end{array}$ & $\begin{array}{l}\text { Global Curvature } \\
\text { Imposed }\end{array}$ \\
\hline$\beta_{k k}$ & $33.235(13.6)$ & - & $-35.699(4.37)$ & - & $-13.136(3.86)$ & - \\
\hline$\beta_{k l}$ & $-46.001(14.8)$ & - & $51.998(8.28)$ & - & $-.9588(5.73)$ & - \\
\hline$\beta_{k e}$ & $109.38(19.3)$ & - & $99.102(16.2)$ & - & $-5.6413(17.0)$ & - \\
\hline$\beta_{l l}$ & $-73.020(29.7)$ & - & $-88.273(11.7)$ & - & $-39.915(10.0)$ & - \\
\hline$\beta_{l e}$ & $-2.7645(19.1)$ & - & $58.524(9.61)$ & - & $50.311(7.30)$ & - \\
\hline$\beta_{e e}$ & $-139.69(27.9)$ & - & $-186.88(21.5)$ & - & $-45.212(21.3)$ & - \\
\hline$\beta_{k t}$ & $-.0136(.009)$ & $-.0115(.008)$ & $.0049(.006)$ & $.0241(.007)$ & $.0051(.003)$ & $.0036(.002)$ \\
\hline$\gamma_{k t}$ & $-.0003(.000)$ & $-.0003(.001)$ & $-.0004(.000)$ & $-.0007(.001)$ & - & - \\
\hline$\beta_{k}$ & $1.8719(.086)$ & $1.8695(.074)$ & $1.3074(.049)$ & $1.2005(.060)$ & $1.1388(.059)$ & $1.1499(.058)$ \\
\hline$\beta_{l t}$ & $-.0227(.004)$ & $-.0181(.006)$ & $-.0018(.005)$ & $-.0008(.006)$ & $-.0164(.001)$ & $-.0166(.001)$ \\
\hline$\gamma_{l t}$ & $.0003(.000)$ & $.0002(.001)$ & $-.0006(.000)$ & $-.0006(.000)$ & - & - \\
\hline$\beta_{l}$ & $1.6577(.035)$ & $1.6471(.039)$ & $2.1718(.047)$ & $2.1671(.050)$ & $1.7896(.040)$ & $1.7895(.037)$ \\
\hline$\beta_{m t}$ & $-.0249(.004)$ & $-.0294(.008)$ & $.0092(.001)$ & $.0098(.002)$ & $.0082(.000)$ & $.0075(.000)$ \\
\hline$\gamma_{m t}$ & $.0005(.000)$ & $.0006(.001)$ & $-0001(.000)$ & $-.0001(.000)$ & - & - \\
\hline$\beta_{m}$ & $.9593(.033)$ & $.9559(.042)$ & $.8160(.012)$ & $0.8117(.015)$ & $.6903(.007)$ & $.6868(.008)$ \\
\hline$\beta_{e t}$ & $-.0241(.008)$ & $-.0259(.008)$ & $.0402(.010)$ & $.0138(.008)$ & $-.0169(.002)$ & $-.0157(.001)$ \\
\hline$\gamma_{e t}$ & $-.0002(.000)$ & $-.0001(.001)$ & $-.0012(.000)$ & $-.0006(.000)$ & - & - \\
\hline$\beta_{e}$ & $2.5201(.077)$ & $2.5391(.076)$ & $1.3875(.087)$ & $1.5420(.074)$ & $1.7348(.039)$ & $1.7433(.039)$ \\
\hline$a_{k k}$ & - & $5.5786(1.26)$ & - & $5.9888(.729)$ & - & $3.3611(.891)$ \\
\hline$a_{k l}$ & - & $3.4976(4.04)$ & - & $-4.9476(2.67)$ & - & 2.1987 (1.37) \\
\hline$a_{k e}$ & - & $-11.749(1.85)$ & - & $-2.4875(1.89)$ & - & $-2.8631(1.83)$ \\
\hline$a_{l l}$ & - & $-10.440(2.52)$ & - & $-6.5599(.913)$ & - & $-6.4141(.580)$ \\
\hline$a_{l e}$ & - & $-3.1756(4.54)$ & - & $9.2811(1.02)$ & - & $7.4143(.822)$ \\
\hline$a_{e e}$ & - & $.0000(1.00)$ & - & $.0000(2.84)$ & - & $-.0000(2.18)$ \\
\hline Curv & 43 & 0 & 43 & 0 & 43 & 0 \\
\hline Log likelihood & 178.68 & 175.09 & 244.0 & 237.16 & 262.76 & 260.85 \\
\hline
\end{tabular}

Notes: Sample period, annual data 1961-2003 $(T=43)$. Standard errors of the parameter estimates are reported in parenthesis. Positivity and monotonicity violations are 0 in each case. 
Table 9: NQ Estimates For US Industries

\begin{tabular}{|c|c|c|c|c|}
\hline \multirow[b]{2}{*}{ Parameter } & \multicolumn{2}{|c|}{ Metal } & \multicolumn{2}{|c|}{ Paper } \\
\hline & $\begin{array}{c}\text { Curvature } \\
\text { Not Imposed }\end{array}$ & $\begin{array}{c}\text { Global Curvature } \\
\text { Imposed }\end{array}$ & $\begin{array}{c}\text { Curvature } \\
\text { Not Imposed }\end{array}$ & Global Curvature \\
\hline$\beta_{k k}$ & $-10112.5(1694.0)$ & - & $-4772.5(510.6)$ & - \\
\hline$\beta_{k l}$ & $-3973.5(1790.2)$ & - & $-3193.0(770.7)$ & - \\
\hline$\beta_{k e}$ & $-517.34(710.0)$ & - & $-233.79(349.7)$ & - \\
\hline$\beta_{l l}$ & $-33785.1(5671.9)$ & - & $-11157.3(2244.8)$ & - \\
\hline$\beta_{l e}$ & 3648.8 (1739.7) & - & $1090.5(679.7)$ & - \\
\hline$\beta_{e e}$ & 457.53 (1070.1) & - & $-803.89(397.4)$ & - \\
\hline$\beta_{k t}$ & $.0013(.001)$ & $.0012(.000)$ & $.0003(.000)$ & $.0003(.000)$ \\
\hline$\gamma_{k t}$ & $.0000(.000)$ & $.0000(.000)$ & $.0000(.000)$ & $.0000(.000)$ \\
\hline$\beta_{k}$ & $.0757(.008)$ & $.0754(.008)$ & $.1044(.003)$ & $.1042(.003)$ \\
\hline$\beta_{l t}$ & $-.0033(.001)$ & $-.0032(.001)$ & $-.0103(.001)$ & $-.0103(.001)$ \\
\hline$\gamma_{l t}$ & $.0001(.000)$ & $.0001(.000)$ & $.0002(.000)$ & $.0002(.000)$ \\
\hline$\beta_{l}$ & $.2481(.013)$ & $.2474(.015)$ & $.3889(.007)$ & $.3991(.007)$ \\
\hline$\beta_{m t}$ & $.0085(.001)$ & $.0083(.001)$ & $.0026(.001)$ & $.0026(.001)$ \\
\hline$\gamma_{m t}$ & $-.0002(.000)$ & $.0002(.000)$ & $-.0001(.000)$ & $-.0001(.000)$ \\
\hline$\beta_{m}$ & $.5836(.016)$ & $.5874(.015)$ & $.5467(.011)$ & $.5468(.013)$ \\
\hline$\beta_{e t}$ & $.0015(.000)$ & $.0016(.000)$ & $.0004(.000)$ & $.0004(.000)$ \\
\hline$\gamma_{e t}$ & $-.0001(.000)$ & $-.0001(.000)$ & $-.0001(.000)$ & $-.0001(.000)$ \\
\hline$\beta_{e}$ & $.0687(.004)$ & $.0656(.003)$ & $.0529(.002)$ & $.0527(.003)$ \\
\hline$a_{k k}$ & - & $101.03(8.71)$ & - & $69.074(4.40)$ \\
\hline$a_{k l}$ & 一 & $38.959(20.9)$ & - & $46.292(14.4)$ \\
\hline$a_{k e}$ & - & $7.0168(7.27)$ & - & $3.4175(5.89)$ \\
\hline$a_{l l}$ & - & $-152.67(28.5)$ & - & $79.915(22.7)$ \\
\hline$a_{l e}$ & - & $23.441(16.7)$ & - & $-15.684(10.9)$ \\
\hline$a_{e e}$ & - & $.0000(5.70)$ & — & $-23.387(9.92)$ \\
\hline Curvature Violations & 43 & 0 & 43 & 0 \\
\hline Log likelihood & 562.84 & 562.63 & 644.08 & 644.02 \\
\hline
\end{tabular}

Notes: Sample period, annual data 1961-2003 $(T=43)$. Standard errors of the parameter estimates are reported in parenthesis. Positivity and monotonicity violations are 0 in each case. 
Table 10: Average Annual Rates of Technical Change (\%) Using Translog

\begin{tabular}{|c|c|c|c|c|c|c|}
\hline & \multicolumn{2}{|c|}{$\begin{array}{c}\text { Autonomous } \\
\text { Technical Change }\end{array}$} & \multicolumn{2}{|c|}{$\begin{array}{c}\text { Biased } \\
\text { Technical Change }\end{array}$} & \multicolumn{2}{|c|}{$\begin{array}{c}\text { Total } \\
\text { Technical Change }\end{array}$} \\
\hline & $\begin{array}{c}\text { Curvature } \\
\text { Not Imposed }\end{array}$ & $\begin{array}{l}\text { Curvature } \\
\text { Imposed }\end{array}$ & $\begin{array}{c}\text { Curvature } \\
\text { Not Imposed }\end{array}$ & $\begin{array}{l}\text { Curvature } \\
\text { Imposed }\end{array}$ & $\begin{array}{c}\text { Curvature } \\
\text { Not Imposed }\end{array}$ & $\begin{array}{c}\text { Curvature } \\
\text { Imposed }\end{array}$ \\
\hline \multicolumn{7}{|l|}{ Canada } \\
\hline Cement & 0.44 & 0.35 & -0.06 & 0.02 & 0.38 & 0.37 \\
\hline \multicolumn{7}{|l|}{ U.S. } \\
\hline $\begin{array}{l}\text { Metal } \\
\text { Paper }\end{array}$ & $\begin{array}{l}0.17 \\
0.20\end{array}$ & $\begin{array}{l}0.18 \\
0.21\end{array}$ & $\begin{array}{l}-0.01 \\
-0.01\end{array}$ & $\begin{array}{l}0.08 \\
0.07\end{array}$ & $\begin{array}{l}0.16 \\
0.19\end{array}$ & $\begin{array}{l}0.26 \\
0.28\end{array}$ \\
\hline
\end{tabular}

Notes: Sample period, annual data 1961-2003 $(T=43)$. All theoretical regularity conditions are satisfied in each case when curvature being imposed.

Table 11: Average Annual Rates of Technical Change (\%) Using GL

\begin{tabular}{lcc}
\hline & Curvature Not Imposed & Local Curvature Imposed \\
\hline Canada & & \\
Cement & 1.12 & 1.44 \\
Paper & 0.28 & - \\
Metal & 1.00 & - \\
\hline U.S. & & - \\
Paper & 0.17 & - \\
\hline
\end{tabular}

Notes: Sample period, annual data 1961-2003 $(T=43)$. All theoretical regularity conditions are satisfied in each case when curvature being imposed.

Table 12: Average Annual Rates of Technical Change (\%) Using NQ

\begin{tabular}{lccccccc}
\hline Curvature & \multicolumn{3}{c}{ Canada } & & \multicolumn{2}{c}{ U.S. } & Curvature \\
\cline { 2 - 4 } Restrictions & Cement & Metal & Paper & & Metal & Paper & Violation \\
\hline No & 1.42 & 1.23 & 0.69 & & 0.16 & 0.20 & Yes \\
Yes & 1.42 & 1.20 & 0.69 & & 0.16 & 0.20 & No \\
\hline
\end{tabular}

Notes: Sample period, annual data 1961-2003 $(T=43)$. Positivity and monotonicity violations are 0 in each case. 
Table 13: Price Elasticities for the Canadian Industries

\begin{tabular}{|c|c|c|c|c|c|}
\hline \multirow[b]{2}{*}{ Factor $i$} & \multirow[b]{2}{*}{ Model } & \multicolumn{4}{|c|}{ Price Elasticities } \\
\hline & & $\eta_{K i}$ & $\eta_{L i}$ & $\eta_{M i}$ & $\eta_{E i}$ \\
\hline \multirow{4}{*}{$\begin{array}{l}\text { Cement } \\
(K)\end{array}$} & & & & & \\
\hline & NQ & -.047 & -.036 & -.091 & .058 \\
\hline & GL & -.248 & -.020 & -.039 & .074 \\
\hline & TL & -.159 & -.048 & .086 & -.148 \\
\hline \multirow[t]{3}{*}{$(L)$} & NQ & -.048 & -.264 & .346 & .067 \\
\hline & GL & -.034 & -.098 & -.035 & .055 \\
\hline & TL & -.112 & -.432 & .243 & .012 \\
\hline \multirow[t]{3}{*}{$(M)$} & NQ & -.064 & -.169 & -.533 & .069 \\
\hline & GL & -.043 & -.022 & -.106 & .045 \\
\hline & TL & .396 & .475 & -.440 & .600 \\
\hline \multirow[t]{3}{*}{$(E)$} & NQ & -.014 & .131 & .278 & -.194 \\
\hline & GL & .326 & .139 & .180 & -.175 \\
\hline & TL & -.125 & .004 & .111 & -.465 \\
\hline \multirow{4}{*}{$\begin{array}{l}\text { Metal } \\
(K)\end{array}$} & & & & & \\
\hline & NQ & -.007 & .001 & -.006 & .002 \\
\hline & GL & -.190 & -.005 & .009 & .012 \\
\hline & TL & -.364 & -.032 & .056 & .009 \\
\hline \multirow[t]{3}{*}{$(L)$} & NQ & .014 & -.124 & -.086 & .168 \\
\hline & GL & -.085 & -.144 & -.010 & .157 \\
\hline & $\mathrm{TL}$ & -.083 & -.435 & .092 & .440 \\
\hline \multirow[t]{3}{*}{$(M)$} & NQ & .011 & -.028 & -.058 & .054 \\
\hline & GL & .088 & -.007 & -.161 & .104 \\
\hline & TL & .437 & .279 & -.144 & -.023 \\
\hline \multirow[t]{3}{*}{$(E)$} & NQ & -.030 & .151 & .150 & -.223 \\
\hline & GL & .186 & .156 & .162 & -.273 \\
\hline & TL & .010 & .188 & -.003 & -.426 \\
\hline \multirow{4}{*}{$\begin{array}{l}\text { Paper } \\
(K)\end{array}$} & & & & & \\
\hline & NQ & -.011 & -.011 & .005 & .009 \\
\hline & GL & -.037 & -.006 & .025 & .007 \\
\hline & TL & -.208 & .004 & .040 & .008 \\
\hline \multirow[t]{3}{*}{$(L)$} & NQ & -.057 & -.144 & -.031 & .133 \\
\hline & GL & -.013 & -.137 & -.004 & .173 \\
\hline & $\mathrm{TL}$ & .009 & -.210 & .051 & .197 \\
\hline \multirow[t]{3}{*}{$(M)$} & NQ & -.017 & -.012 & -.020 & .014 \\
\hline & GL & .037 & -.003 & -.080 & .050 \\
\hline & TL & .191 & .113 & -.143 & .248 \\
\hline \multirow[t]{3}{*}{$(E)$} & NQ & .056 & .166 & .046 & -.156 \\
\hline & GL & .012 & .146 & .059 & -.230 \\
\hline & $\mathrm{TL}$ & .008 & .094 & .053 & -.452 \\
\hline
\end{tabular}

Notes: Sample period, annual data 1961-2003 $(T=43)$. Elasticities are calculated at the middle year of the sample period. 
Table 14: Morishima Elasticities for the Canadian Industries

\begin{tabular}{|c|c|c|c|c|c|}
\hline \multirow[b]{2}{*}{ Factor $i$} & \multirow[b]{2}{*}{ Model } & \multicolumn{4}{|c|}{ Morishima Elasticities } \\
\hline & & $\sigma_{K i}$ & $\sigma_{L i}$ & $\sigma_{M i}$ & $\sigma_{E i}$ \\
\hline \multirow{4}{*}{$\begin{array}{l}\text { Cement } \\
(K)\end{array}$} & & & & & \\
\hline & NQ & - & .010 & -.044 & .105 \\
\hline & GL & - & .229 & .209 & .323 \\
\hline & TL & - & .112 & .246 & .012 \\
\hline \multirow[t]{3}{*}{$(L)$} & NQ & .216 & - & .610 & .330 \\
\hline & GL & .063 & - & .063 & .153 \\
\hline & TL & .320 & - & .675 & .444 \\
\hline \multirow[t]{3}{*}{$(M)$} & NQ & .470 & .702 & - & .602 \\
\hline & GL & .063 & .084 & - & .151 \\
\hline & TL & .836 & .916 & - & 1.04 \\
\hline \multirow[t]{3}{*}{$(E)$} & NQ & .180 & .325 & .472 & - \\
\hline & GL & .501 & .314 & .355 & - \\
\hline & TL & .340 & .469 & .575 & - \\
\hline \multirow{4}{*}{$\begin{array}{l}\text { Metal } \\
(K)\end{array}$} & & & & & \\
\hline & NQ & - & .008 & .001 & .009 \\
\hline & GL & - & .185 & .199 & .202 \\
\hline & TL & - & .332 & .420 & .373 \\
\hline \multirow[t]{3}{*}{$(L)$} & NQ & .138 & - & .038 & .292 \\
\hline & GL & .059 & - & .133 & .301 \\
\hline & TL & .353 & - & .527 & .875 \\
\hline \multirow[t]{3}{*}{$(M)$} & NQ & .069 & .030 & - & .112 \\
\hline & GL & .249 & .154 & - & .265 \\
\hline & TL & .582 & .424 & - & .121 \\
\hline \multirow[t]{3}{*}{$(E)$} & NQ & .193 & .374 & .373 & - \\
\hline & GL & .460 & .429 & .436 & - \\
\hline & TL & .436 & .614 & .423 & - \\
\hline \multirow{4}{*}{$\begin{array}{l}\text { Paper } \\
(K)\end{array}$} & & & & & \\
\hline & NQ & - & .000 & .016 & .020 \\
\hline & GL & - & .030 & .062 & .044 \\
\hline & TL & - & .212 & .248 & .216 \\
\hline \multirow[t]{3}{*}{$(L)$} & NQ & .086 & - & .113 & .276 \\
\hline & GL & .123 & - & .133 & .310 \\
\hline & TL & .220 & - & .261 & .407 \\
\hline \multirow[t]{3}{*}{$(M)$} & NQ & .003 & .008 & - & .034 \\
\hline & GL & .118 & .078 & - & .131 \\
\hline & TL & .334 & .256 & - & .391 \\
\hline \multirow[t]{3}{*}{$(E)$} & NQ & .212 & .322 & .201 & - \\
\hline & GL & .243 & .376 & .289 & - \\
\hline & TL & .460 & .546 & .505 & - \\
\hline
\end{tabular}

Notes: Sample period, annual data 1961-2003 $(T=43)$. Elasticities are calculated at the middle year of the sample period. 
Table 15: Price Elasticities for the U.S. Industries

\begin{tabular}{|c|c|c|c|c|c|}
\hline \multirow[b]{2}{*}{ Factor $i$} & \multirow[b]{2}{*}{ Model } & \multicolumn{4}{|c|}{ Price Elasticities } \\
\hline & & $\eta_{K i}$ & $\eta_{L i}$ & $\eta_{M i}$ & $\eta_{E i}$ \\
\hline \multirow{4}{*}{$\begin{array}{l}\text { Metal } \\
(K)\end{array}$} & & & & & \\
\hline & NQ & -.048 & -.136 & .158 & -.011 \\
\hline & GL & -.557 & .016 & .046 & -.020 \\
\hline & TL & -.362 & .069 & .039 & -.218 \\
\hline \multirow[t]{3}{*}{$(L)$} & NQ & -.122 & -.381 & .368 & .017 \\
\hline & GL & .077 & -.085 & .033 & -.015 \\
\hline & TL & .404 & -.171 & .000 & .241 \\
\hline \multirow[t]{3}{*}{$(M)$} & NQ & -.091 & .487 & -.675 & .109 \\
\hline & GL & .529 & .077 & -.088 & .049 \\
\hline & TL & .497 & .001 & -.125 & .444 \\
\hline \multirow[t]{3}{*}{$(E)$} & NQ & .189 & .030 & .148 & -.114 \\
\hline & GL & -.048 & -.007 & .010 & -.013 \\
\hline & TL & -.539 & .101 & .086 & -.466 \\
\hline \multirow{4}{*}{$\begin{array}{l}\text { Paper } \\
(K)\end{array}$} & & & & & \\
\hline & NQ & -.168 & -.059 & .173 & .016 \\
\hline & GL & -.281 & -.112 & .110 & -.058 \\
\hline & TL & -.189 & -.084 & .090 & -.058 \\
\hline \multirow[t]{3}{*}{$(L)$} & NQ & -.071 & -.031 & .045 & .030 \\
\hline & GL & -.269 & -.422 & .227 & .112 \\
\hline & TL & -.320 & -.667 & .375 & .491 \\
\hline \multirow[t]{3}{*}{$(M)$} & NQ & -.059 & .046 & -.328 & .077 \\
\hline & GL & .585 & .505 & -.344 & .060 \\
\hline & TL & .568 & .619 & -.456 & -.057 \\
\hline \multirow[t]{3}{*}{$(E)$} & NQ & .274 & .044 & .110 & -.123 \\
\hline & GL & -.036 & .029 & .007 & -.115 \\
\hline & TL & -.059 & .132 & -.009 & -.376 \\
\hline
\end{tabular}

Notes: Sample period, annual data 1961-2003 $(T=43)$. Elasticities are calculated at the middle year of the sample period. 
Table 16: Morishima Elasticities for the U.S. Industries

\begin{tabular}{|c|c|c|c|c|c|}
\hline \multirow[b]{2}{*}{ Factor $i$} & \multirow[b]{2}{*}{ Model } & \multicolumn{4}{|c|}{ Morishima Elasticities } \\
\hline & & $\sigma_{K i}$ & $\sigma_{L i}$ & $\sigma_{M i}$ & $\sigma_{E i}$ \\
\hline \multirow{4}{*}{$\begin{array}{l}\text { Metal } \\
(K)\end{array}$} & & & & & \\
\hline & NQ & - & -.089 & .206 & .037 \\
\hline & GL & - & .573 & .603 & .537 \\
\hline & TL & - & .431 & .401 & .144 \\
\hline \multirow{3}{*}{$(L)$} & NQ & .259 & - & .368 & .397 \\
\hline & GL & .161 & - & .118 & .070 \\
\hline & TL & .574 & - & .171 & .412 \\
\hline \multirow[t]{3}{*}{$(M)$} & NQ & .584 & 1.16 & - & .783 \\
\hline & GL & .618 & .165 & - & .137 \\
\hline & TL & .622 & .125 & - & .568 \\
\hline \multirow[t]{3}{*}{$(E)$} & NQ & .303 & .144 & .263 & - \\
\hline & GL & -.035 & .006 & .023 & - \\
\hline & TL & -.072 & .568 & .552 & - \\
\hline \multirow{3}{*}{$\begin{array}{l}\text { Paper } \\
(K)\end{array}$} & NQ & - & 109 & 341 & 184 \\
\hline & GL & - & .169 & .391 & .223 \\
\hline & TL & - & .105 & .279 & .131 \\
\hline \multirow[t]{3}{*}{$(L)$} & NQ & -.039 & - & .077 & .062 \\
\hline & GL & .154 & - & .649 & .535 \\
\hline & TL & .347 & - & 1.04 & 1.16 \\
\hline \multirow[t]{3}{*}{$(M)$} & NQ & .269 & .374 & - & .404 \\
\hline & GL & .929 & .849 & - & .404 \\
\hline & TL & 1.02 & 1.08 & - & .398 \\
\hline \multirow[t]{3}{*}{$(E)$} & NQ & .397 & .167 & .233 & - \\
\hline & GL & .079 & .144 & .122 & - \\
\hline & TL & .317 & .508 & .367 & - \\
\hline
\end{tabular}




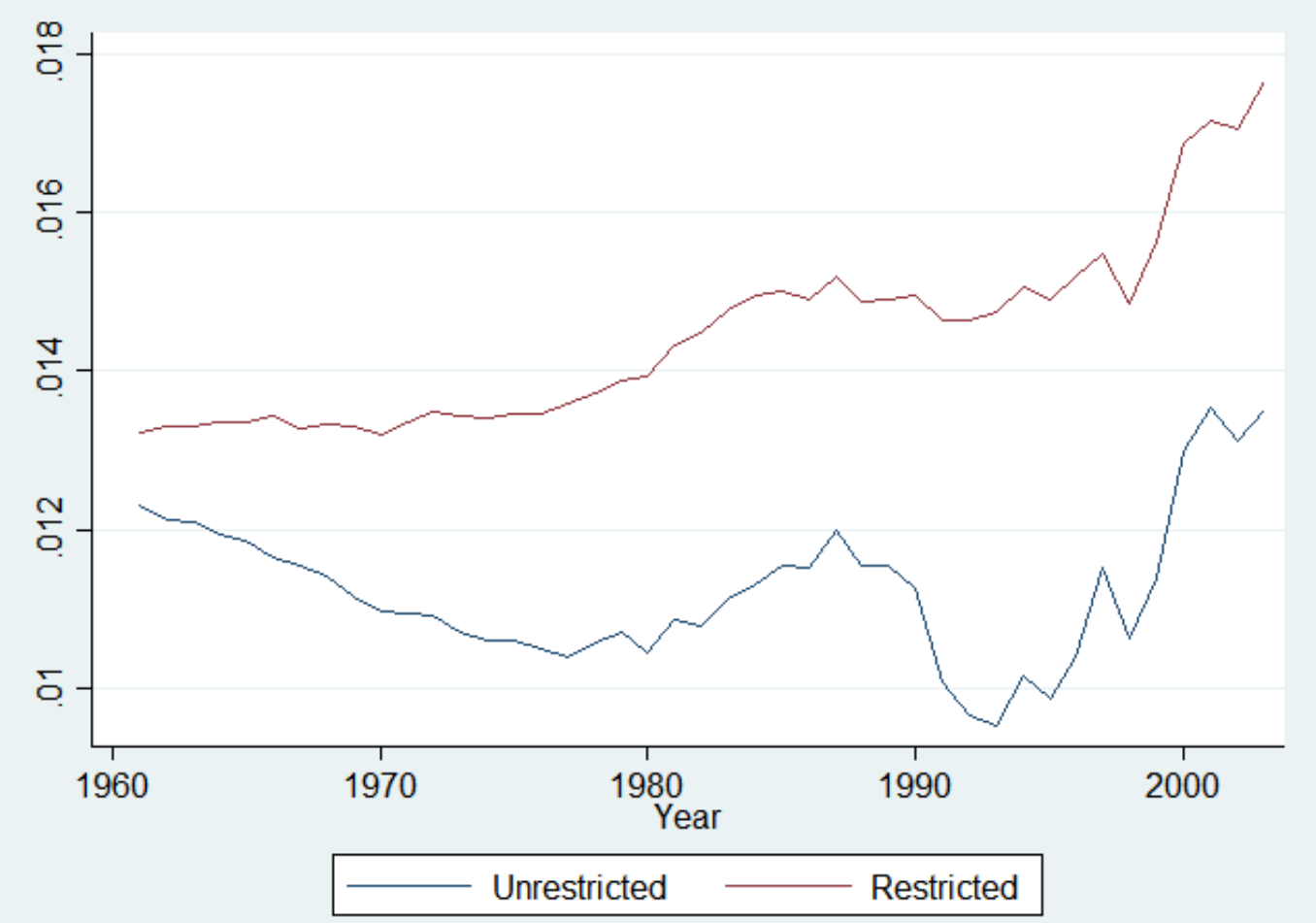

Figure 1: Total Factor Productivity in Canadian Cement Industry Using GL 


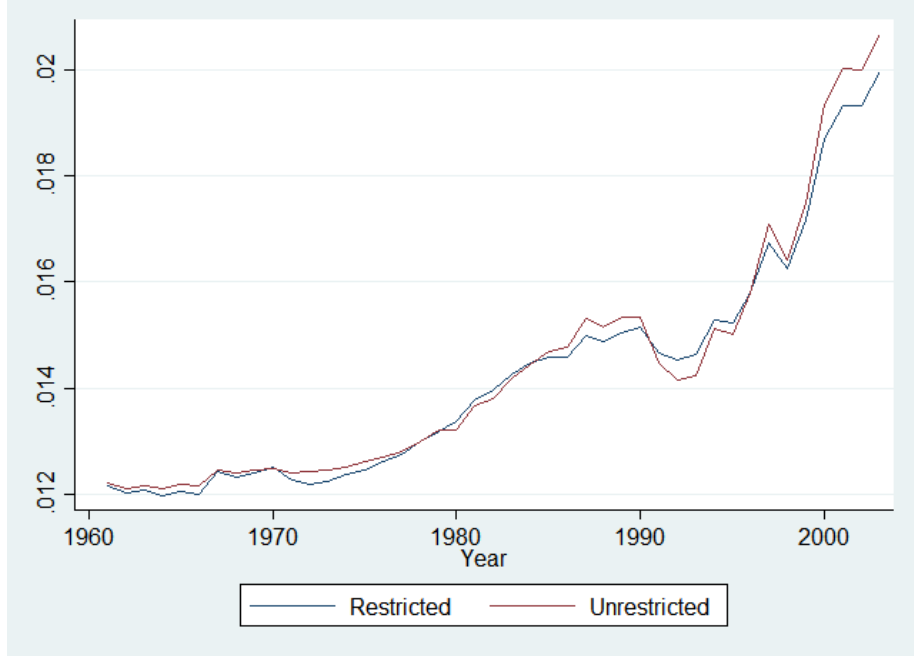

(a) Cement

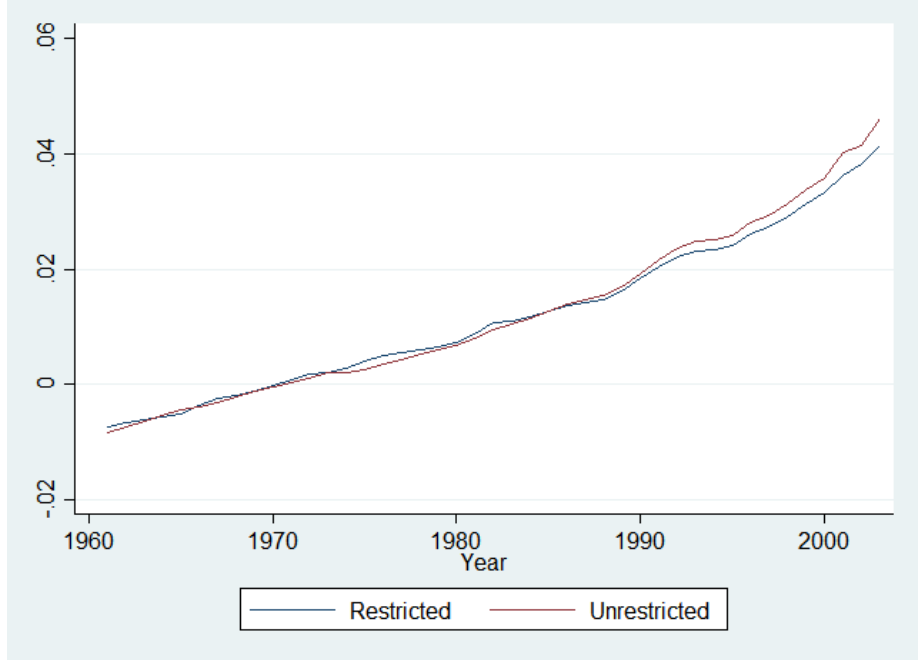

(b) Metal

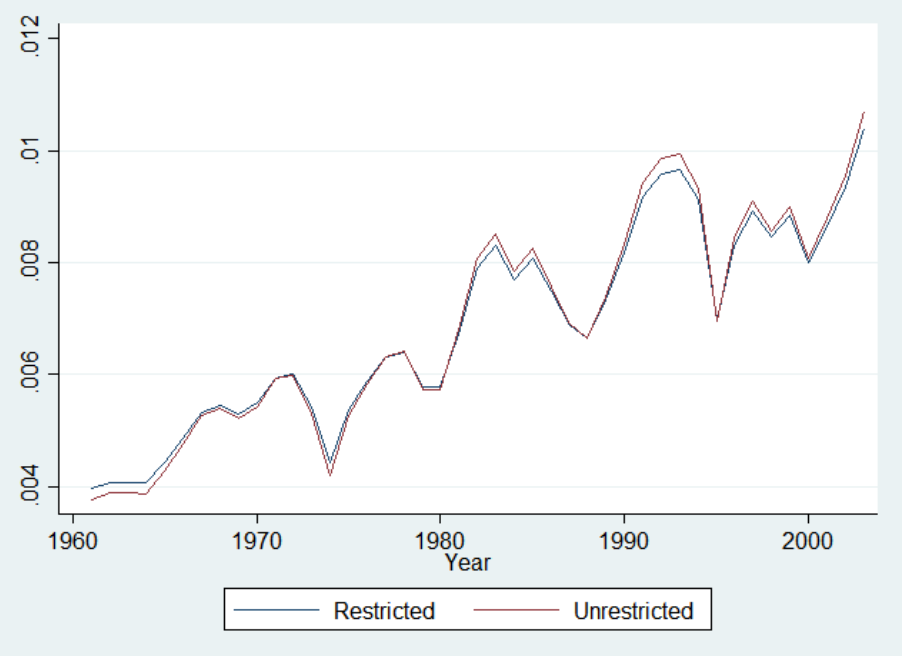

(c) Paper

Figure 2: Total Factor Productivity in Canadian Manufacturing Using NQ 


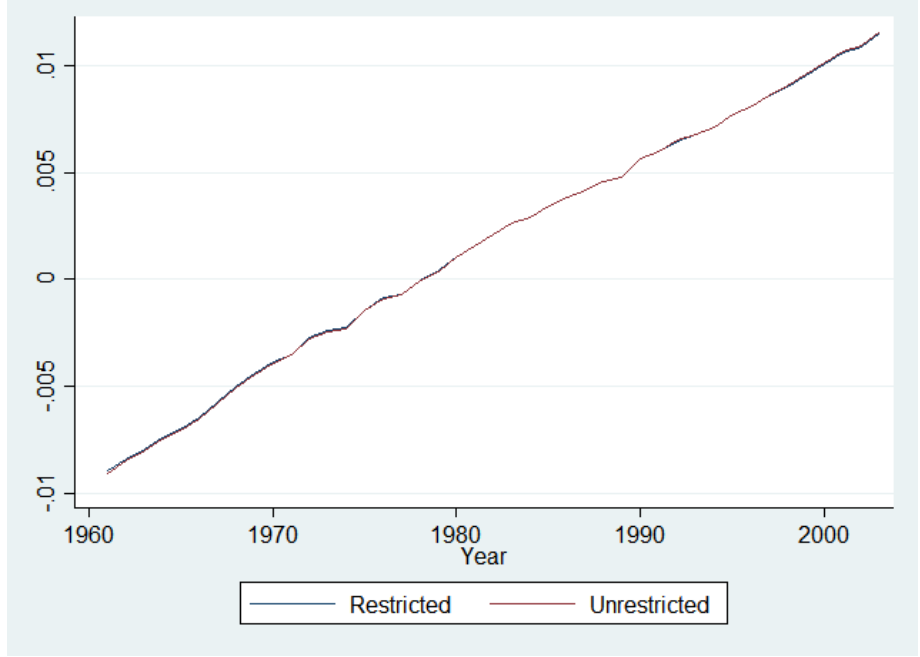

(a) Metal

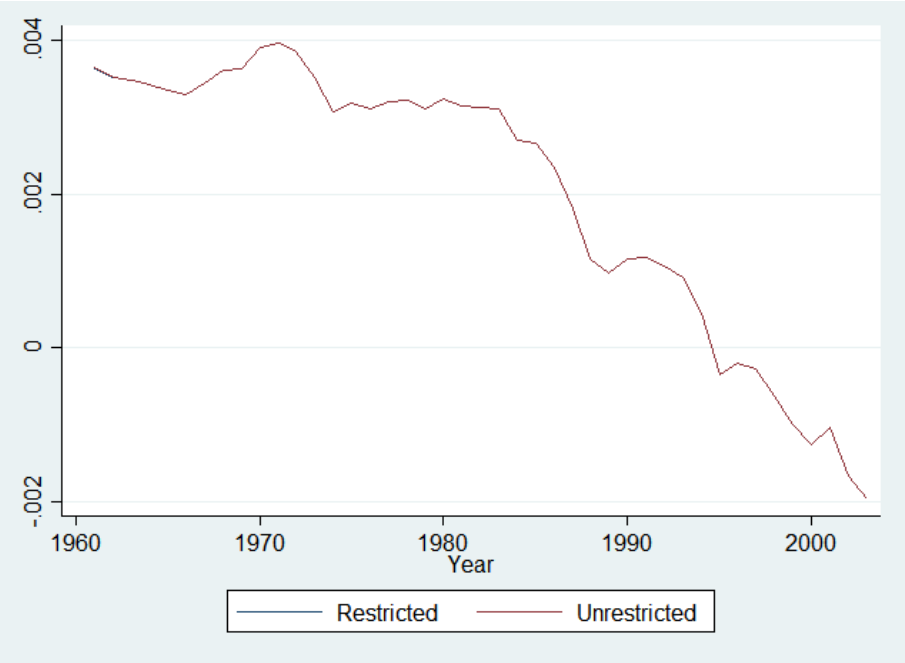

(b) Paper

Figure 3: Total Factor Productivity in U.S. Manufacturing Using NQ 


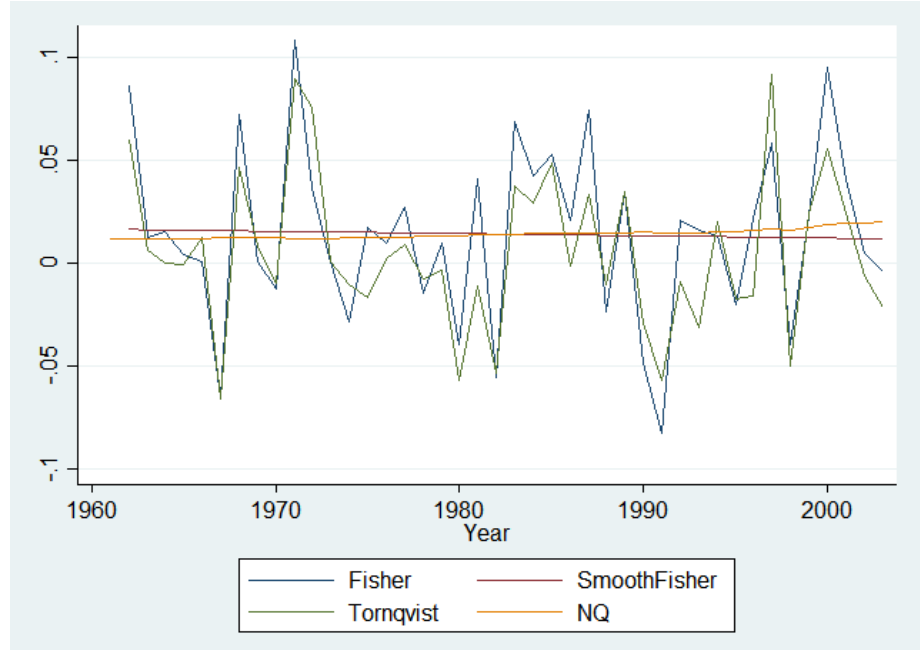

(a) Cement

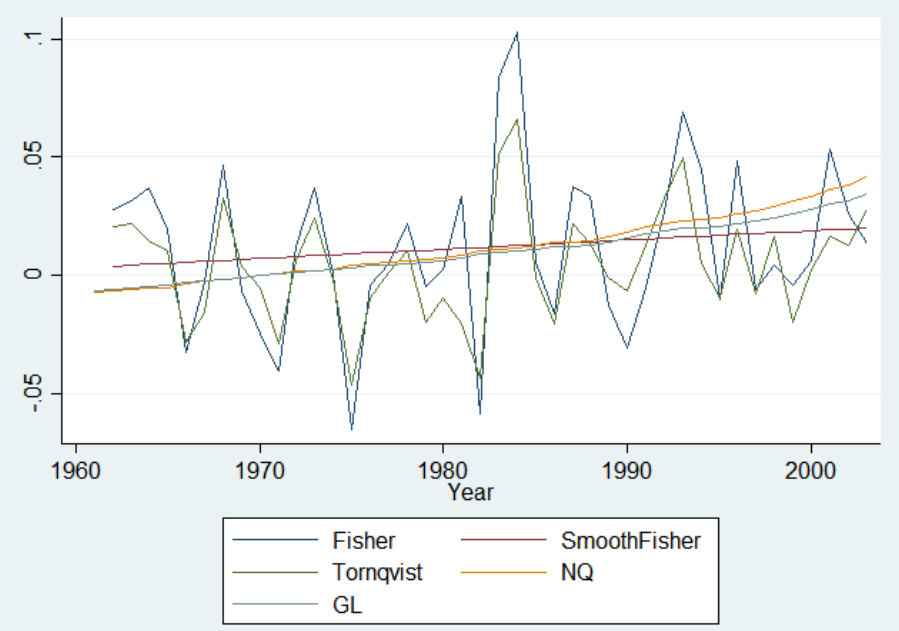

(b) Metal

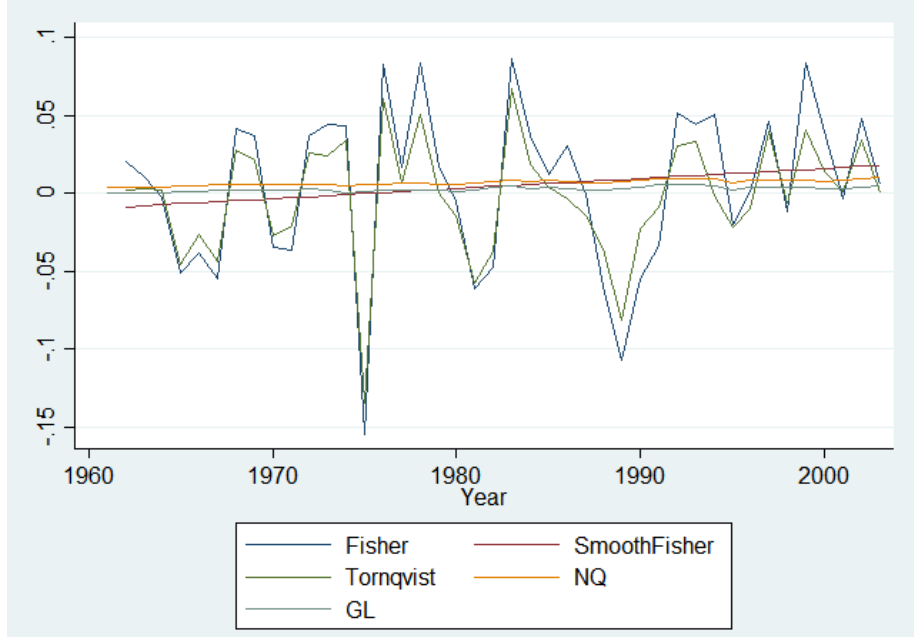

(c) Paper

Figure 4: Total Factor Productivity in Canadian Manufacturing 


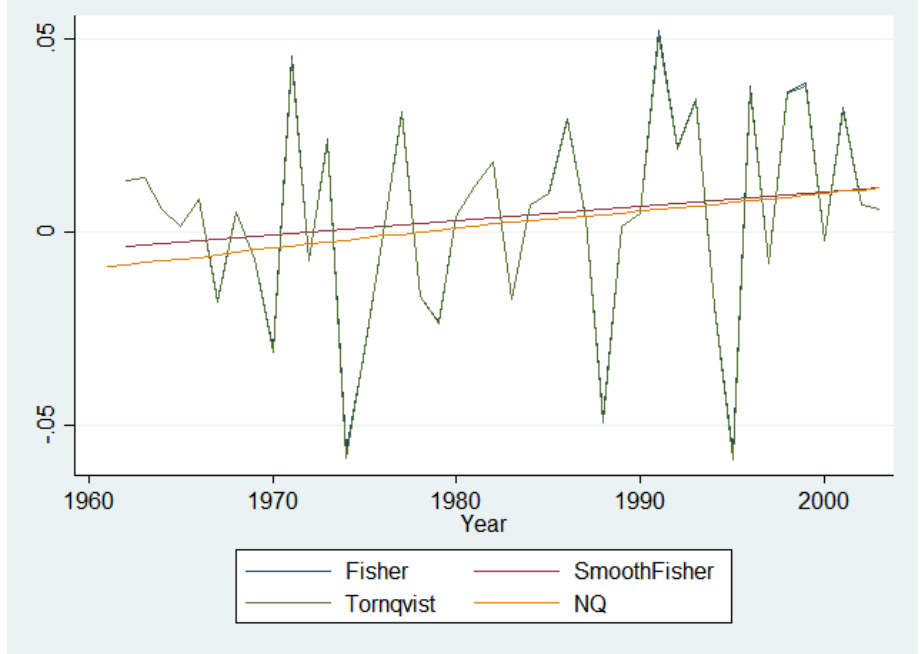

(a) Metal

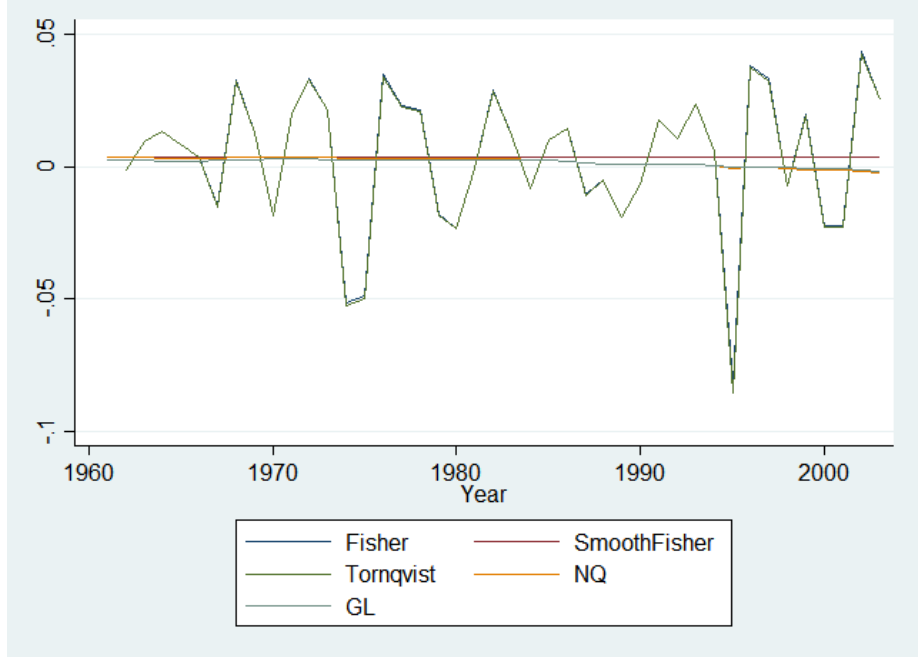

(b) Paper

Figure 5: Total Factor Productivity in U.S. Manufacturing 


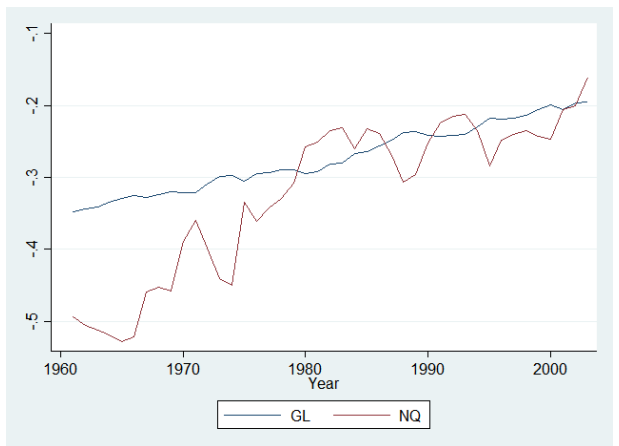

(a) Capital

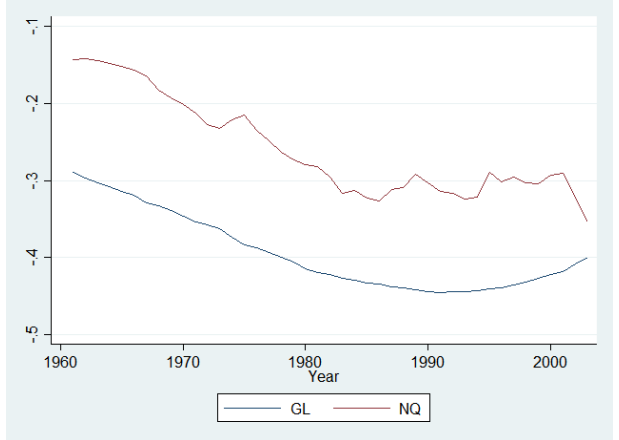

(b) Labour

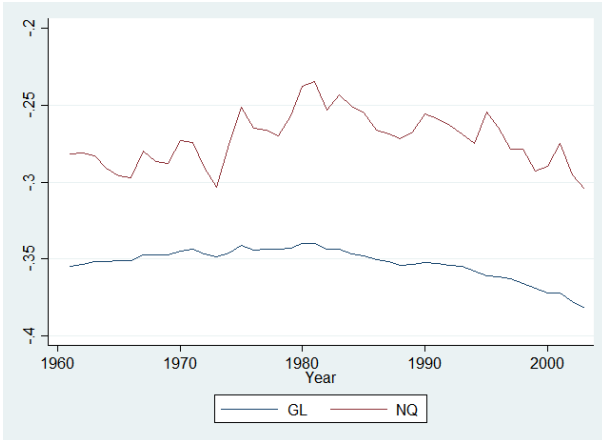

(c) Material

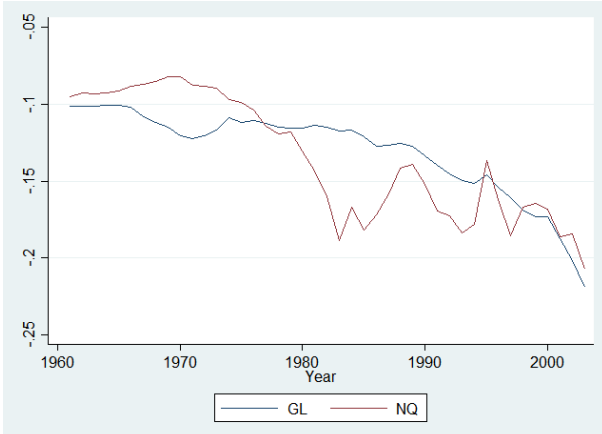

(d) Energy

Figure 6: Own Price Elasticites in U.S. Paper Industry 